\title{
A model for hydraulic redistribution incorporating coupled soil-root moisture transport
}

\author{
G. G. Amenu and P. Kumar \\ Department of Civil and Environmental Engineering, University of Illinois, Urbana, IL 61801, USA \\ Received: 17 September 2007 - Published in Hydrol. Earth Syst. Sci. Discuss.: 4 October 2007 \\ Revised: 7 December 2007 - Accepted: 10 December 2007 - Published: 24 January 2008
}

\begin{abstract}
One of the adaptive strategies of vegetation, particularly in water limited ecosystems, is the development of deep roots and the use of hydraulic redistribution which enables them to make optimal use of resources available throughout the soil column. Hydraulic redistribution refers to roots acting as a preferential pathway for the movement of water from wet to dry soil layers driven by the moisture gradient - be it from the shallow to deep layers or vice versa. This occurs during the nighttime while during the daytime moisture movement is driven to fulfill the transpiration demand at the canopy. In this study, we develop a model to investigate the effect of hydraulic redistribution by deep roots on the terrestrial climatology. Sierra Nevada eco-region is chosen as the study site which has wet winters and dry summers. Hydraulic redistribution enables the movement of moisture from the upper soil layers to deeper zones during the wet months and this moisture is then available to meet the transpiration demand during the late dry season. It results in significant alteration of the profiles of soil moisture and water uptake as well as increase in the canopy transpiration, carbon assimilation, and the associated water-use-efficiency during the dry summer season. This also makes the presence of roots in deeper soil layers much more important than their proportional abundance would otherwise dictate. Comparison with observations of latent heat from a flux tower demonstrates improved predictability and provides validation of the model results. Hydraulic redistribution serves as a mechanism for the interaction between the variability of deep layer soil-moisture and the land-surface climatology and could have significant implications for seasonal and subseasonal climate prediction.
\end{abstract}

Correspondence to: P. Kumar

(kumar1@uiuc.edu)

\section{Introduction}

Plants are known to exhibit an evolutionary adaptation to adverse environmental pressures. This includes unique growth forms that increase competitiveness for light and water. By shifting the balances of environmental stresses in favor of the plant, the adaptation increases the plant's chances of survival and productivity. One of such unique adaptations that has received increasing attention over the last two decades is the deep-rooting nature of plants (Stone and Kalisz, 1991; Canadell et al., 1996; Jackson et al., 1999) and the associated phenomenon known as "hydraulic lift" (Richards and Caldwell, 1987; Caldwell and Richards, 1989; Dawson, 1993, 1996; Caldwell et al, 1998), or recently termed as "hydraulic redistribution" (Burgess et al., 1998, 2000, 2001; Hultine et al., 2003, 2004; Brooks et al., 2002, 2006). Root systems of plants are known to extend vertically into the soil for considerable depths and tap water and nutrients from both deep and shallow soil layers, that is, they exhibit patterns of uptake of water and nutrients in accordance with the variability of resources at different soil depths.

The term "hydraulic lift" (hereinafter, HL) refers to the passive movement of water via plant roots from deep moister soil layers to shallow drier soil layers. The term hydraulic redistribution (hereinafter, HR) is a general term that incorporates both the upward, and the downward transfer of water, i.e. from shallower layers to deeper layers via roots (inverse HL) (Schulze et al., 1998; Smith et al., 1999). Thus, HR can be defined as "a passive movement of water via plant roots from relatively moist soil layers to drier soil layers". In HR, plant roots form a conveyance system between soil layers through which water is transported.Therefore, moisture gets absorbed and released in response to gradients in water potential between the roots and the soil. This is in agreement with the theory for water movement in soil-plant-atmosphere continuum (SPAC), in which water transport is governed by water potential gradient (Dixon, 1914; van den Honert, 1948; Philip, 1966; Kramer and Boyer, 1995).

Published by Copernicus Publications on behalf of the European Geosciences Union. 


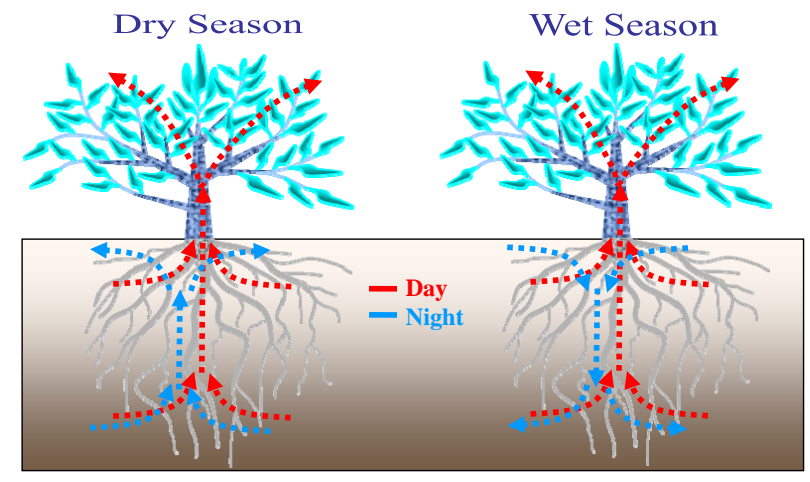

Fig. 1. Schematic description of the hydraulic redistribution.

Figure 1 shows a schematic of the hydraulic redistribution. During transpiration from the leaves, the open stomata creates water potential gradient between the leaves and the roots, resulting in net water movement from the soil to the roots and then to the leaves. Water is absorbed from all depths depending upon the potential gradient and passes into the transpiration stream at the leaves. This is true both during wet and dry seasons. When the stomata close, it results in turgor pressure that increases water potential within the plant body. As the potential in the root exceeds the potential in the drier part of the soil, moisture starts to efflux from the root to the dry soil, while water still continues to flow into the roots in the wetter part of the soil. During dry seasons, the upper soil is often drier than the deeper part of the soil, and the net water transport via the roots during night is thus upwards, from deeper to shallower layers, as shown in the left-panel of Fig. 1. On the other hand, during wet seasons, the upper soil layers get wetter than the deeper layers, and the net water movement through the roots will be downwards as shown in the right-panel of Fig. 1.

Hydraulic redistribution is a reverse flow, in the sense, that the moisture transport occurs in the reverse direction, from the root to the soil, than what transpiration dictates. The origin and evolution of this phenomenon is not clear yet, but there is much experimental evidence that shows its existence in numerous plant species (Table 1). This evidence, coming from both laboratory and field experimental studies, shows that this process moves water through the soil profile at a much faster rate than could have been possible by gravity and diffusion in the soil matrix alone.

Though the majority of the documented cases of HR are for arid and semi-arid environments, given the phenomenon is dictated by water potential gradients, it undoubtedly is a feature in any vegetated environment experiencing waterlimitation in parts of the root system (Oliveira et al. 2005). If root systems span a suitable water potential gradient, HR should be expected as long as there is no impediment to the reverse flow, that is, the efflux of water from the roots, and considerable evidence supports this hypothesis.

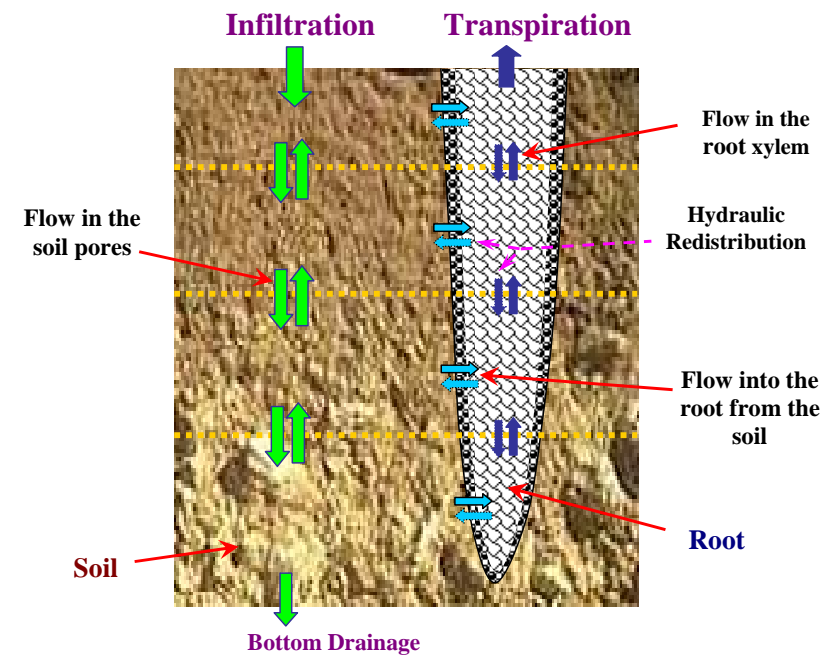

Fig. 2. Conceptual view of the hydraulic redistribution model as used in this study.

Water-limitation, even if it occurs for short periods, is a feature of most biomes (Caldwell et al., 1998), and the necessary water potential gradients for HR may exist sporadically or regularly in many soils. The diversity of species represented in Table 1 also suggest that HR may occur in a large number of plant species, rather than limited to particular plant groups; though the quantity of hydraulically distributed water may depend directly on the depth to which roots penetrate the soil and the ability of the plants to maintain conductive root systems in relatively dry soil. These could portray the mechanism of HR as a general root system phenomenon, widespread both in species and ecosystems. The widespread nature of HR calls for the necessity of incorporating plantwater transport dynamics into ecosystem and climate models where it has been traditionally overlooked.

The objective of this study is to develop a physicallybased model of HR and to investigate its role in influencing the terrestrial eco-climatology. Of paramount importance is the effect of HR on soil climatology and fluxes at the landatmosphere interface. In Sect. 2 we present the derivation of the HR model. Section 3 describes the study site and sources of model input datasets. In Sect. 4 we provide the results and discussions, followed by summary of the main points in Sect. 5.

\section{Modeling hydraulic redistribution}

Traditionally, the water uptake by plant roots in land-surface models is parameterized as a function of transpiration $E_{t}$, soil moisture content $\theta_{\text {root }}$ of the root zone, and the root distribution $\rho_{\text {root }}$ within the soil profile. That is,

$S=f\left(E_{t}, \theta_{\text {root }}, \rho_{\text {root }}\right)$ 
Table 1. Some laboratory and field evidences of hydraulic redistribution by plant roots.

\begin{tabular}{lll}
\hline Source & Plant Species & Study Site \\
\hline Mooney et al. (1980) & Shrubs & Atacama Desert, Chile \\
van Bavel \& Baker (1985) & Bermudagrass & Lab Experiment \\
Corak et al. (1987) & Alfalfa & Lab Experiment \\
Richards \& Caldwell (1987) & Sagebrush, Grass & Utah, USA \\
Baker \& van Bavel (1988) & Cotton & Lab Experiment \\
Caldwell \& Richards (1989) & Sagebrush, Grass & Utah, USA \\
Dawson (1993) & Sugar Maples & New York, USA \\
Wan et al. (1993) & Broom Snakeweed & Texas, USA \\
Dawson \& Pate (1996) & Proteaceous trees & Western Australia \\
Emerman \& Dawson (1996) & Sugar Maples & New York, USA \\
Burgess et al. (1998) & Silky Oak & Kenya, Africa \\
Burgess et al. (1998) & Eucalyptus tree & Western Australia \\
Yoder \& Nowak (1999) & Shrubs, Grasses & Mojave Desert, Nevada, USA \\
Burgess et al. (2000) & Proteaceous tree & Western Australia \\
Millikin \& Bledsoe (2000) & Blue Oaks & California, USA \\
Song et al. (2000) & Sunflower & Lab Experiment, Kansas \\
Wan et al. (2000) & Maize & Lab Experiment \\
Brooks et al. (2002) & Ponderosa pine & Oregon, USA \\
Brooks et al. (2002) & Douglas-fir & Washington, USA \\
Ludwig et al. (2003) & Savanna trees & Tanzania, Africa \\
Moreira et al. (2003) & Savanna & Central Brazil \\
Espeleta et al. (2004) & Oaks, bunch grass & South Carolina, USA \\
Hultine et al. (2004) & Leguminous tree & Arizona, USA \\
Leffler et al. (2005) & Cheatgrass & Rush Valley, Utah, USA \\
Oliveira et al. (2005) & Amazon trees & Brazil \\
Brooks et al. (2006) & Douglas-fir & Washington, USA \\
\hline
\end{tabular}

where $S$ is the water extracted by roots, and it is incorporated as a sink term in the Richards equation for vegetated environments, given as

$\frac{\partial \theta}{\partial t}=\frac{\partial}{\partial z}\left[K_{s h}\left(\frac{\partial \psi_{s m}}{\partial z}-1\right)\right]-S$

where $\theta(z)$ is the volumetric soil moisture content, $t$ is time, $K_{s h}(z)$ is soil hydraulic conductivity, $\psi_{s m}(z)$ is soil matric potential, and $z$ is depth. For notational convenience, explicit dependence of the variables on $z$ is dropped, henceforth. There are several variants of Eq. (1), as can be seen from the formulations in current land surface models (e.g. Liang et al., 1994; Wetzel and Boone, 1995; Dai et al., 2003; Oleson et al., 2004). However, they do not incorporate the flow dynamics within the root system, and hence, the importance of moisture redistribution via plant roots.

Modeling the effect of moisture redistribution by plant roots demands the consideration of flow in the root system in conjunction with flow in the soil. In such a modeling approach, plant roots can be viewed as a continuum like the soil media. While it may not be practical to model flow in individual roots, macroscopic approaches that consider the root system as a whole, that is, a "big root" model, might be considered for such purposes. In the past, very few attempts have been made to model HR (e.g. Ryel et al., 2002; Ren et al., 2004; Lee et al., 2005). These models, however, parameterize the hydraulic redistribution as a function of the water potential between different soil layers and do not model the actual pathway for moisture movement within the plant system. The present work is distinct in that we have developed a physically-based dynamic model of HR that includes two way moisture movements through the coupled soil-root transport system.

Our approach of modeling HR couples water flows within the soil and root media, where flow in both media is governed by the water potential gradient and the hydraulic conductivities of the systems. The root is assumed to absorb moisture from and/or release moisture to the soil, depending on the water potential gradient. In doing so, the root system is considered as a conduit for moisture transport from wet soil reservoirs to dry soil reservoirs, while at the same time conveying moisture to fulfill the transpiration demand at the canopy. Governing equations for flow through both soil and root are solved as a set of coupled equations. Figure 2 shows a schematic description of the model. A detailed derivation of the root model, as developed in this study, is presented next. 


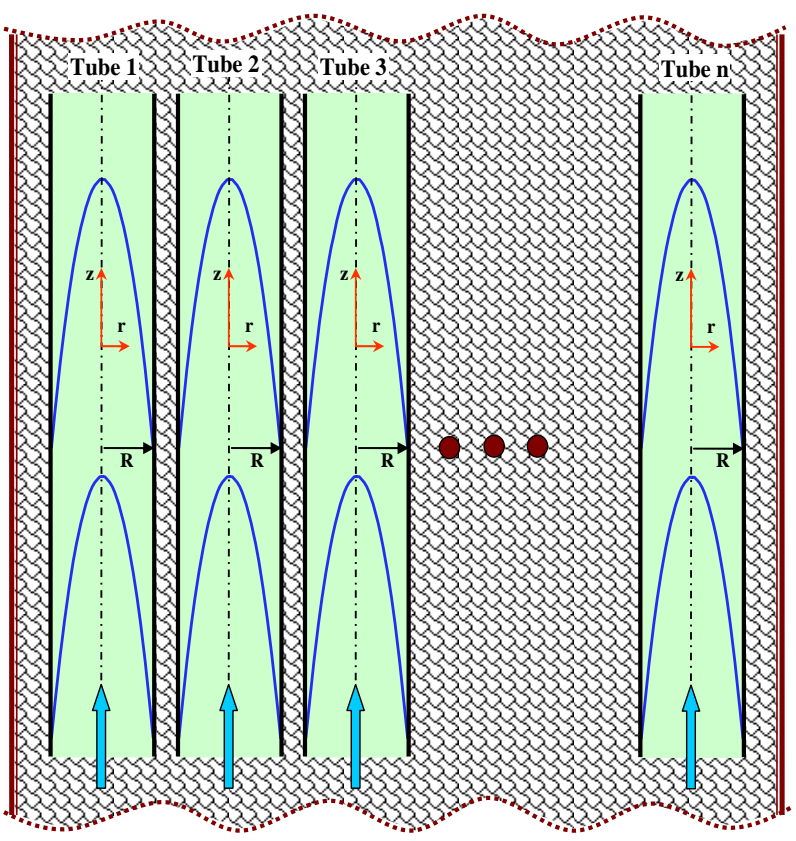

Fig. 3. Parallel xylem conduits as conceptualized for a root system: $R$ represents the radius of the conduit, $z$ and $r$ shows the vertical and radial directions, respectively, the arrows indicate the flow direction, and the parabolic curve indicates the velocity profile across the tube.

Plant roots can be viewed as a network of pipes consisting of xylem tubes (Gurevitch et al., 2002; Tyree and Zimmermann, 2002) that convey water from the soil to the stem, from where it is distributed to the leaves. In this system, the flow is governed by pressure gradient established by the transpiration demand at the leaves, resulting in water being "pulled". Assuming root xylem conduits as cylindrical tubes conveying laminar flow, the velocity profile in the tubes takes a parabolic shape, with maximum at the center of the tube and minimum at the boundaries (e.g. see Kundu and Kohen, 2002). Assuming vertical flow and accounting for gravity, the velocity distribution across the tube is expressed as

$u(r)=\left(\frac{r^{2}-R^{2}}{4 \mu}\right)\left(\frac{\partial p_{\text {xylem }}}{\partial z}+\rho g\right)$

where $u(r)$ is velocity at a radial distance $r$ from the center of the tube, $R$ is the radius of the tube, $\mu$ is the viscosity of the water in the tube, and $p_{\text {xylem }}$ is the pressure in the xylem tube, $\rho$ is density of water in the tube, and $g$ is the gravitational acceleration. The flow rate $Q_{\text {xylem }}$ is then given by

$Q_{\mathrm{xylem}}=\int_{0}^{R} 2 \pi r u(r) d r=-\frac{\pi R^{4}}{8 \mu}\left(\frac{\partial p_{\mathrm{xylem}}}{\partial z}+\rho g\right)$.

Equation (4) is the well known Hagen-Poiseuille equation for vertical pipes. Denoting $\left[K_{\mathrm{xylem}}=\pi R^{4} / 8 \mu\right]$ to represent the hydraulic conductivity of the pipe, the above equation can be rewritten as

$Q_{\text {xylem }}=-K_{\text {xylem }}\left(\frac{\partial p_{\text {xylem }}}{\partial z}+\rho g\right)$.

For a system of roots with $n$ number of xylem tubes (see Fig. 3), the total flow rate in the root system is additive of the flow rates of individual tubes. In other words, the conductivities are additive for parallel vessels, provided that the pressure gradient driving the flow is the same in all vessels. Thus, the axial conductivity of a root system can be approximated as

$K_{r h, a x}=\sum_{i=1}^{n} K_{\text {xylem, } \mathrm{i}}$

where $K_{r h, a x}$ is the root system hydraulic conductivity in the axial direction, and $K_{\text {xylem, }}$ is the hydraulic conductivity of the $i^{\text {th }}$ xylem vessel in the system of $n$ vessels. This is an important assumption that enables a macroscopic characterization at the root system scale from the microscopic characterization at the individual xylem scale. Thus, the flow rate for the root system, $Q_{\text {root }}$, can be expressed as

$Q_{\text {root }}=-K_{r h, a x}^{\prime}\left(\frac{\partial p_{\text {root }}}{\partial z}+\rho g\right)$

where $p_{\text {root }}$ is the mean pressure in the root system. In the above equation, the hydraulic conductivity $K_{r h, a x}^{\prime}$ has dimension of $\left[\mathrm{L}^{4} \mathrm{~T}^{-1} \mathrm{~Pa}^{-1}\right]$ and the flow rate $Q_{\text {root }}$ has dimension of $\left[\mathrm{L}^{3} \mathrm{~T}^{-1}\right]$. In terms of root pressure potential $\psi_{r p}$, Eq. (7) can be written as

$Q_{\text {root }}=-K_{r h, a x}^{\prime \prime}\left(\frac{\partial \psi_{r p}}{\partial z}+1\right)$

where $K_{r h, a x}^{\prime \prime}$ now has the same dimension as $Q_{\text {root }}\left[\mathrm{L}^{3} \mathrm{~T}^{-1}\right]$. The water flux (flow rate per unit ground area) through the root system can then be approximated as

$q_{\mathrm{root}}=-K_{r h, a x}\left(\frac{\partial \psi_{r p}}{\partial z}+1\right)$

in which the dimension of $q_{\text {root }}$ and $K_{r h, a x}$ becomes [LT ${ }^{-1}$ ]. Note that $K_{r h, a x}$ and $\psi_{r p}$ are functions of the soil depth $z$.

Assuming that there is a balance between water flowing into and out of the root system, that is, assuming no storage within the root, and using continuity we get

$\frac{\partial q_{\text {root }}}{\partial z}=S$

where $S$ is the source term (inflow rate into the root) and equal to the sink term for the soil in Eq. (2). Substitution of Eq. (9) into (10) leads to a governing equation for flow in the root system,

$-\frac{\partial}{\partial z}\left[K_{r h, a x}\left(\frac{\partial \psi_{r p}}{\partial z}+1\right)\right]=S$. 

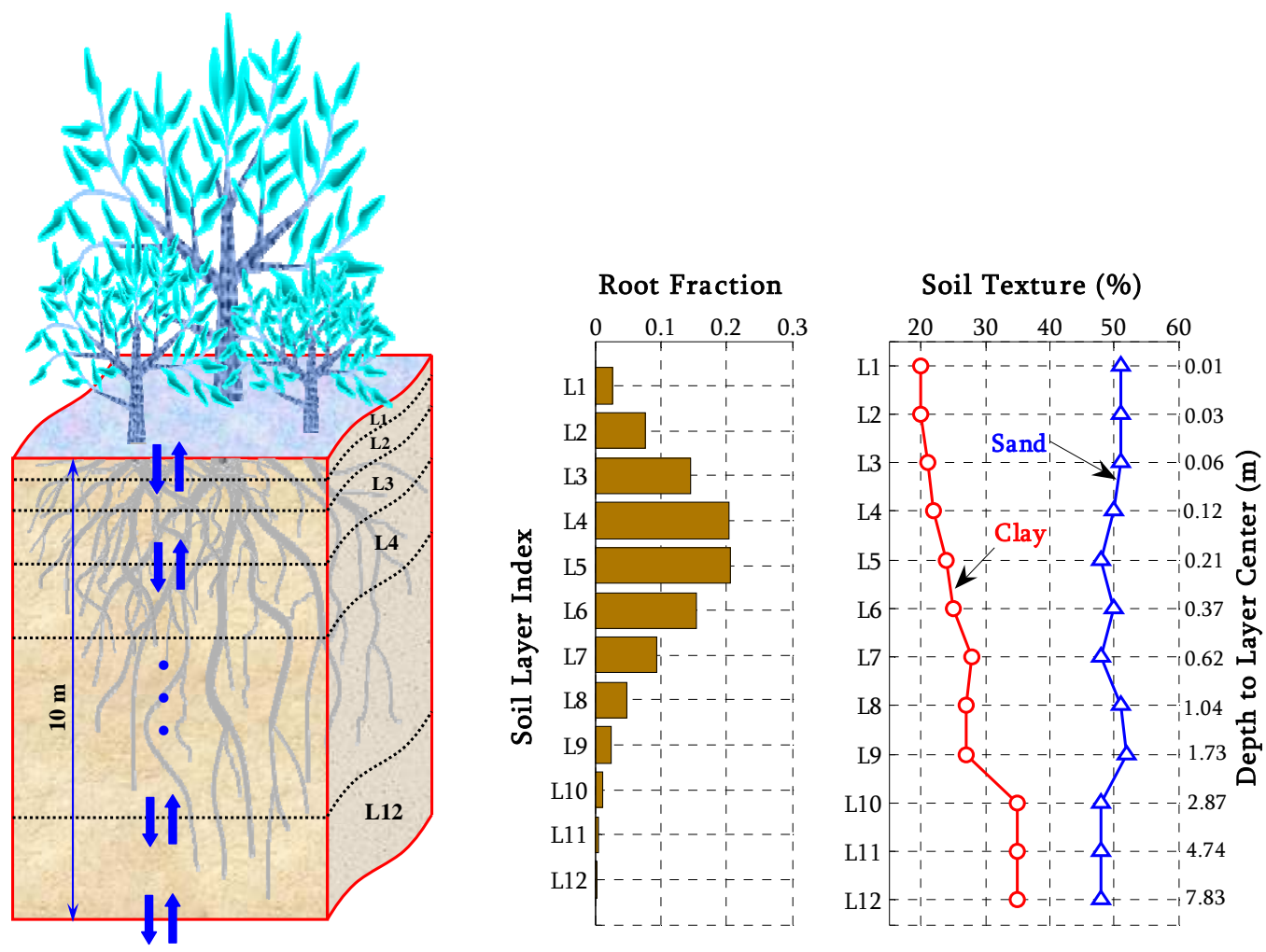

Fig. 4. (left) Schematic view of soil layers. (middle) profile of fraction of roots and (right) profile of soil texture in each soil layer for the study site depicted in Fig. 5.

The governing equations of flow in soil media [Eq. (2)] and in root media [Eq. (11)] are linked by the sink/source term $S$. Modeling of the hydraulic redistribution demands a sink/source term that allows water flow in both directions - from the soil to the root and from the root to the soil depending on the water potential difference between the soil and the root xylem. One very important assumption we make here is that root membrane is equally permeable in both directions.

Water goes through complicated pathways in entering the root xylem from the soil media (see Steudle and Peterson, 1998; Steudle, 2000; Taiz and Zeiger, 2002; Gregory, 2006). A practical way of modeling such complex process is to treat the entire multi-cellular pathway, from the root hairs to the root xylem, as if it is a single permeable membrane. Such a simplification is important for adopting a unified hydraulic conductivity for the radial path, that is, from the soil to the xylem tube. The main forces governing water transport between the soil and the root xylem are the pressure and osmotic potentials. Thus, the water flux between the soil and the root xylem is given by (Fiscus, 1975)

$S=K_{r h, r a d}\left(\Delta \psi_{p}-\Delta \psi_{o}\right)$

where $K_{r h, r a d}$ is the root hydraulic conductivity in the radial direction, $\Delta \psi_{p}$ is pressure potential difference between the soil and the root xylem, and $\Delta \psi_{o}$ osmotic potential difference between the soil and the root xylem. Note that, water potential difference, instead of water potential gradient, is used in the above expression. This is done as it is impractical to know the distance water travels between the soil and the root xylems.

Several experimental studies (e.g. Kramer, 1932; Frensch and Steudle, 1989; Tyree and Zimmermann, 2002) have indicated that the rate of movement of water by osmosis across a multi-cellular root membrane is very slow (10-20 time smaller) as compared to water passage across the membrane by pressure gradient between the soil and the root xylem vessels. This indicates that sufficient water could not enter the roots of an actively transpiring plant by such osmosis processes to replace the water lost by transpiration. It was understood that when a plant is transpiring rapidly enough to set up a tension in the water conducting xylem vessels, this tension continues from the xylem across the root membrane into the soil, and would result in an inflow of water from the soil into the xylem through the membranes. Thus, $\Delta \psi_{o}$ can be assumed negligible (as it is much smaller than $\Delta \psi_{p}$, except for saline environments). With this assumption, Eq. (12) becomes

$S=K_{r h, r a d} \Delta \psi_{p}=K_{r h, r a d}\left(\psi_{s m}-\psi_{r p}\right)$. 


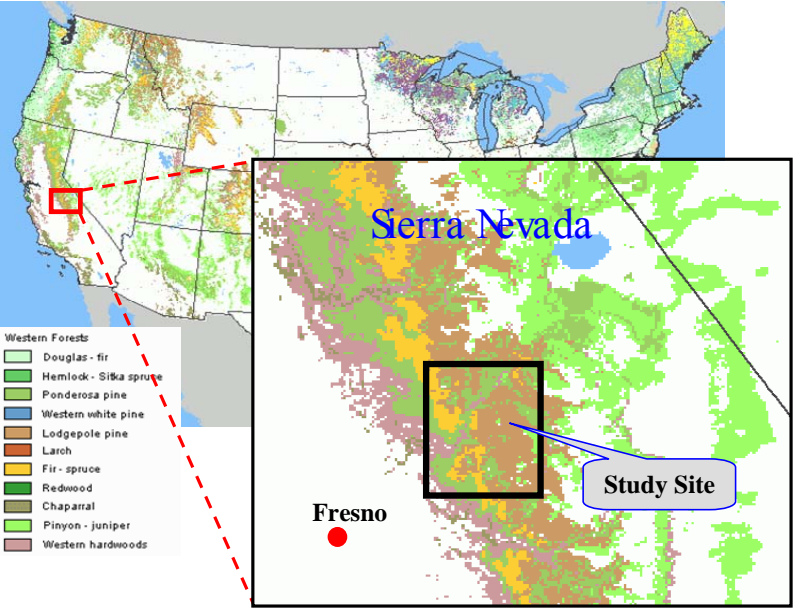

Fig. 5. Location and forest cover of the Sierra Nevada study site. (Source: http://nationalatlas.gov/).

Substituting Eq. (13) into Eqs. (2) and (11), we arrive at the two basic governing equations for modeling HR:

$$
\left.\begin{array}{l}
\frac{\partial \theta}{\partial t}-\frac{\partial}{\partial z}\left[K_{s h}\left(\frac{\partial \psi_{s m}}{\partial z}-1\right)\right]=-K_{r h, r a d}\left(\psi_{s m}-\psi_{r p}\right) \\
-\frac{\partial}{\partial z}\left[K_{r h, a x}\left(\frac{\partial \psi_{r p}}{\partial z}+1\right)\right]=K_{r h, r a d}\left(\psi_{s m}-\psi_{r p}\right)
\end{array}\right\}
$$

Both equations are functions of water potentials of the soil and the root, and need to be solved simultaneously using numerical techniques by dividing the vertical column into layers. One parameter that needs more elaboration is the hydraulic conductivity of the roots. A study by Campbell (1991) suggested that root resistance in any soil layer is directly proportional to the total root resistance and inversely proportional to the fraction of roots in that layer. Based on this concept, the root conductivity in any soil layer can be assumed directly proportional to both the total conductivity of the root system and the root fraction in that layer. Further, studies have reported the soil moisture dependence of root conductivity (e.g. Nobel et al., 1990; Lopez and Nobel, 1991; Wan et al., 1994; Huang and Nobel, 1994; Steudle and Frensch, 1996). Taking all these into consideration, the root hydraulic conductivity in $i^{\text {th }}$ soil layer is assumed to be a function of the total root conductivity of the root system $K_{\text {root, total }}$, the root fraction in that layer $F_{\text {root, i, }}$, and the relative soil saturation of that layer $\left[\theta / \theta_{\mathrm{sat}}\right]_{i}$. Thus,

$$
\begin{aligned}
\left.K_{r h}\right|_{i} & =\left.\left(F_{\text {root }} \cdot \frac{\theta}{\theta_{\text {sat }}}\right)\right|_{i} K_{\text {root, total }} \text { or } \\
\left.K_{r h}\right|_{i} & =\left.\left(F_{\text {root }}\left(\frac{\psi_{s m}}{\psi_{\text {sat }}}\right)^{(-1 / b)}\right)\right|_{i} K_{\text {root, total }}
\end{aligned}
$$

where $\theta_{\text {sat }}$ is soil moisture content at saturation (i.e. soil porosity, and " $\mathrm{b}$ " is the exponent in the Brooks-Corey relationship in Eqs. (A1) and (A2)). Typical values of the radial root conductivity is in the order of $10^{-10} \mathrm{~mm} \mathrm{~s}^{-1}$ per unit $\mathrm{mm}$ of water potential difference between the soil and the root xylem (e.g. see Huang and Nobel, 1994), while that of the axial root conductivity is in the order of $10^{-3} \mathrm{~mm} \mathrm{~s}^{-1}$ per unit water potential gradient along the root (e.g. see Pate et al., 1995). To obtain similar order of magnitudes using Eq. (15), while at the same time allowing variation with soil depth, we set the value of $K_{\text {root, total }}$ to $5 \times 10^{-8} \mathrm{~s}^{-1}$ in the radial and $2 \times 10^{-1} \mathrm{~mm} \mathrm{~s}^{-1}$ in the axial directions (also, see Table A1). These values are by no means perfect, but are reasonable order of magnitudes based on the availability of limited observations in the field. The hydraulic conductivity and matric potential of the soil are functions of the soil moisture content and the soil texture (Clapp and Hornberger, 1978; Oleson et al., 2004), and are described in the appendix [see Eqs. (A1-A6)].

The root fraction $F_{\text {root }}$ is modeled following the methodology of Schenk and Jackson (2002), who, using a global root profile database consisting of more than 500 data points, have developed a two-parameter root distribution model that takes the form of a logistic function. Derived from their model, the root fraction in a given $i^{t h}$ soil layer of thickness $\Delta z_{i}$ can be obtained as

$$
\left.\begin{array}{c}
F_{\text {root }, i}=-\Delta z_{i} \frac{c}{z_{50}}\left(\frac{z_{i}}{z_{50}}\right)^{c-1}\left[1+\left(\frac{z_{i}}{z_{50}}\right)^{c}\right]^{-2} \\
c=\frac{1.27875}{\log \left(z_{50}\right)-\log \left(z_{95}\right)}
\end{array}\right\}
$$

where $z_{i}$ is depth from the surface to the center of the $i^{t h}$ soil layer, and $z_{50}$ and $z_{95}$ are $50^{\text {th }}$ and $95^{\text {th }}$ percentile rooting depths, respectively, that is, depths from the surface above which $50 \%$ and $95 \%$ of all roots are located. The values of $z_{50}$ and $z_{95}$ are dependent on plant functional types.

Eqs. (14), (15), and (16) provide the complete model for HR of the "big-root" model described above. In the coupled system of governing Eq. (14), we have two differential equations (one for the soil and one for the root) and three unknowns: the soil moisture content $\theta$, the soil matric potential $\psi_{s m}$, and the root pressure potential $\psi_{r p}$. Since $\theta$ and $\psi_{s m}$ are related [see Eq. (A2)], the two equations are sufficient for solving the problem numerically using a finite-difference scheme.

To facilitate the numerical solution, the soil column is discretized into 12 soil layers (see Fig. 4). In order to resolve more soil layers near the surface, where the moisture gradient is generally strong, an exponentially increasing soil layer thickness with depth is adopted. Further, to account for deep roots, the total soil depth is set to $10 \mathrm{~m}$ for all of the simulations. Also given in Fig. 4 are the profiles of root fraction and soil texture for the study site (see Sect. 3 for descriptions of the study site and the data source).

The bottom boundary condition for the soil model is set to the hydraulic conductivity of the bottom soil layer, whereas the upper boundary condition is set to the infiltration rate, 
which is modeled as the minimum of throughfall and available capacity in the top soil layer, that is,

$$
\left.\begin{array}{l}
q_{\text {inf } l}=\min \\
\left.q_{\text {through }}=q_{\text {rain }} e e_{\text {through }}, \frac{\Delta z_{1}}{\Delta t}\left(\theta_{\text {sat }, 1}-\theta_{1}\right)\right)
\end{array}\right\}
$$

where $q_{\text {through }}$ is throughfall, $q_{\text {rain }}$ is gross precipitation rate, and $\zeta$ is a constant, $L A I$ is leaf area index, $\Delta z_{1}$ is the thickness of top soil layer, $\theta_{1}$ is moisture content of the top soil layer, $\theta_{\mathrm{sat}, 1}$ is the moisture content at saturation of the top soil layer, and $\Delta t$ is the model time step. The equation for throughfall assumes that the amount of rain intercepted by the canopy is a function of the $L A I$, specifically of the form $d q / d L=-$ constant $q$, where $L$ is the $L A I$. The second part of Eq. (17) results from the integration from the top of the canopy $\left(q=q_{\text {rain }}\right)$ to the ground $\left(q=q_{\text {through }}\right)$. The first part of equation says that the infiltration will not exceed the available capacity of the first soil-layer to take in the water for a computational time step of $\delta \mathrm{t}$ units. The bottom boundary condition for the root model is set to no flux boundary condition, and the upper boundary condition is set to the transpiration rate. The "big-leaf" approach of Penman-Monteith (Monteith and Unsworth, 1990) is used to model the transpiration from the canopy and is described in the Appendix.

The model presented above makes some important assumptions such as

- It assumes that the entire root system is absorbing and this does not change with time.

- It ignores the flow resistance offered by the end wall pitpore membranes that connect xylem conduits (Hacke et $\mathrm{al}, 2006)$.

- It does not incorporate temperature induced changes in water viscosity and root hydraulic properties.

- It does not incorporate limitations in HR due to the changes in nighttime stomatal conductances.

These assumptions may be relaxed through future work and when data becomes available to enable better parameterization across different plant functional types.

\section{Study site and model input data}

The target geographical area for this study is vegetated environment characterized by deep-rooting and water-limitation, such as the vegetated areas of arid and semi-arid climates. A site within the Sierra Nevada ecosystem is selected for this study, which lies at $119^{\circ} 00^{\prime}-119^{\circ} 30^{\prime} \mathrm{W}$ longitude and $37^{\circ} 00^{\prime}-37^{\circ} 30^{\prime} \mathrm{N}$ latitude (see Fig. 5). The climate of the area is characterized by long dry summer and wet winter (see Fig. 6), with average annual precipitation of about $850 \mathrm{~mm}$ and average temperature of about $11^{\circ} \mathrm{C}$.
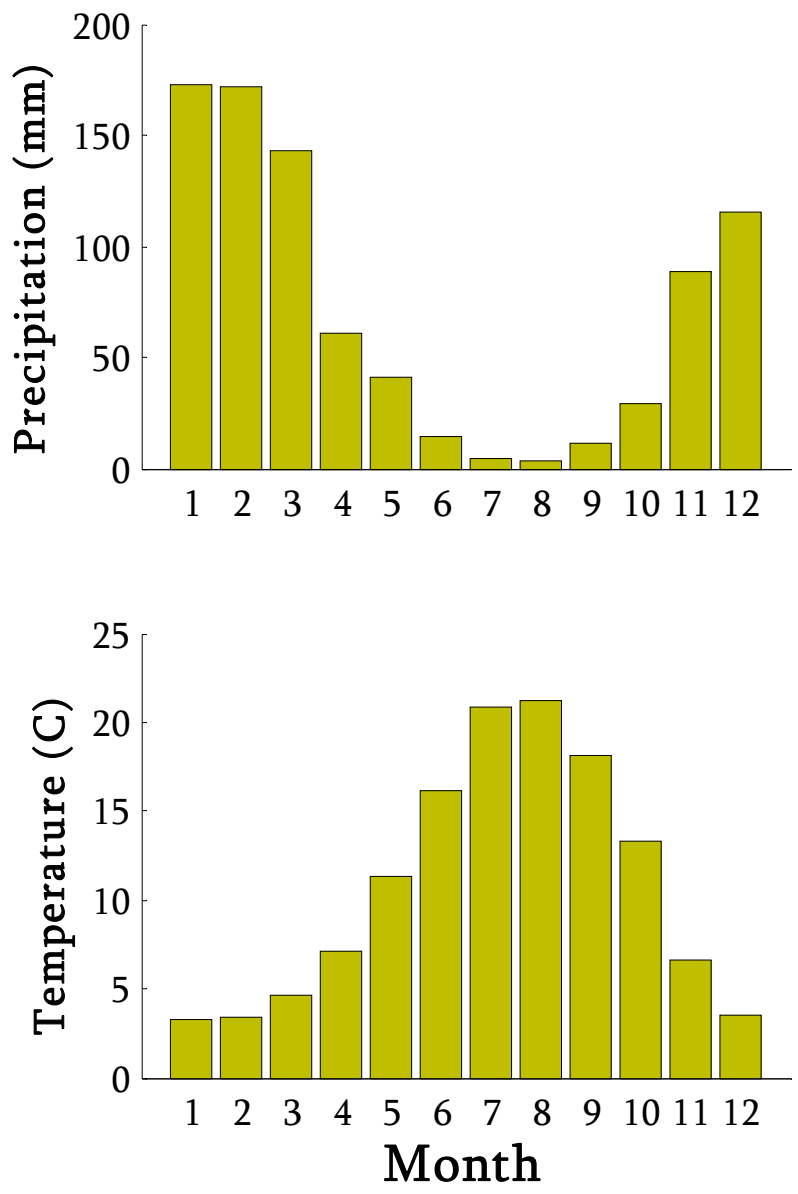

Fig. 6. Seasonality of precipitation (left) and temperature (right) at the Sierra Nevada study site as obtained from North American Regional Reanalysis (NARR) dataset.

The dominant vegetation of the site includes lodgepole pine, ponderosa pine, fir-spruce, and hardwoods (see Fig. 5). Vegetation at lower elevations is dominated by lodgepole pine (Pinus contorta) on the east and ponderosa pine ( $\mathrm{Pi}$ nus ponderosa) and hardwoods on the west, with fir, spruce, and alpine tundra occupying the higher elevations. Vegetation in the region is known to have deep-root systems. For example, the study by Hellmers et al. (1955) in southern California reports plants with roots as deep as $8.5 \mathrm{~m}$. Much of the roots were found penetrating weathered rocks underlying shallow soils. DeSouza et al. (1986) observed rooting depth of greater than $13 \mathrm{~m}$ for shrubs in the region. The work of Lewis and Burgy (1964) reveals a depth of $23 \mathrm{~m}$ for roots of oak tree plants in the area. Through excavation of fractured sandstone in southern California, Thomas and Davis (1989) observed $5.5 \mathrm{~m}$ root depth for chaparral plants. A study by Cannon (1914) reports a root depth of $11 \mathrm{~m}$ for the area.

The HR model described in the previous section requires several input datasets, which can be grouped into two classes: atmospheric and surface data. The atmospheric forcing data 

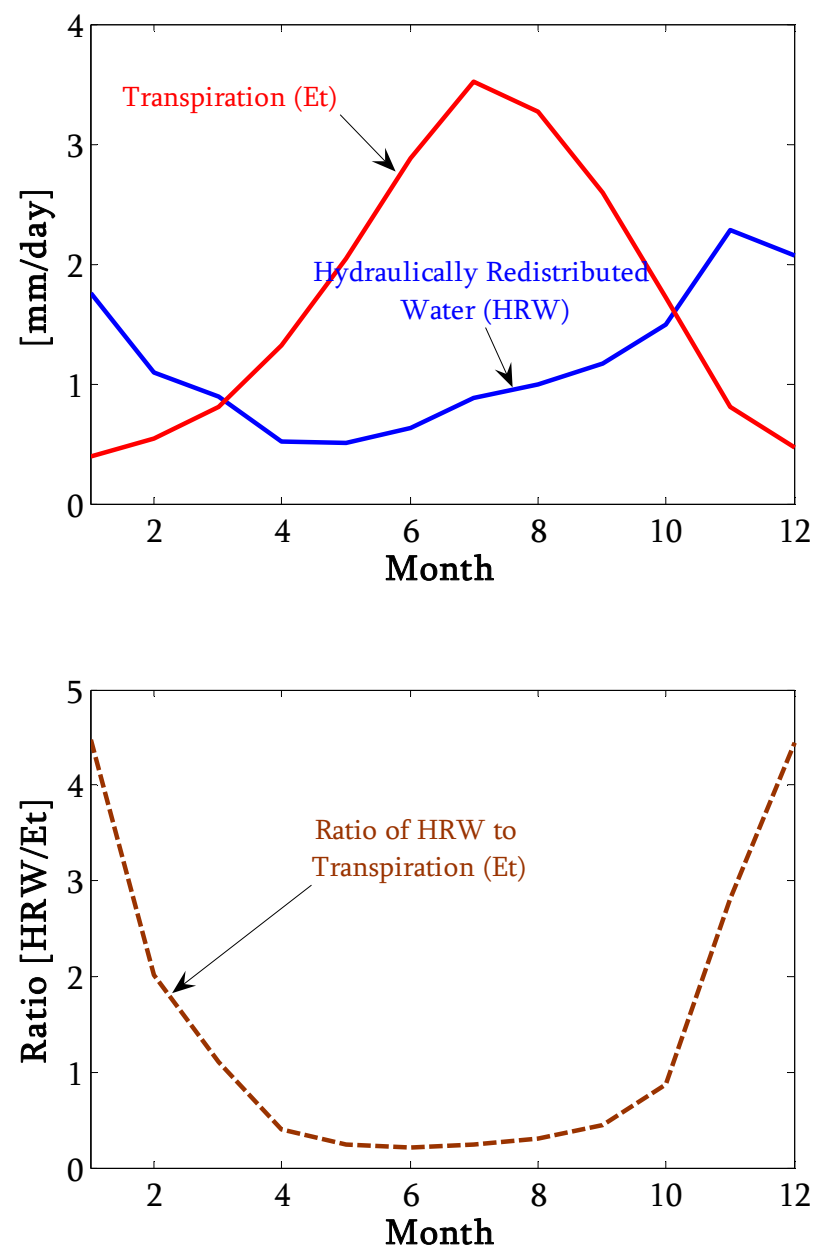

Fig. 7. Comparison of the hydraulically redistributed water (HRW) and the transpiration (Et) for the study site.

includes precipitation, temperature, solar radiation, humidity, wind speed, and pressure. For the study site, these datasets are extracted from the North American Regional Reanalysis (NARR) dataset (Mesinger et al., 2006) for the period 1979-2005. NARR data is a long-term (1979-present) climate dataset covering the North American Continent. It has spatial resolution of $32 \mathrm{~km}$ and temporal resolution of $3 \mathrm{~h}$. The data is disaggregated from its original $3 \mathrm{~h}$ resolution to the model's time step (which is $30 \mathrm{~min}$ ) using linear interpolation.

The surface dataset for the model includes the soil and vegetation data. The model requires the vertical profile of soil texture data (\% clay and \% sand) to compute the hydraulic and thermal properties of the soil. This data is obtained from the International Geosphere-Biosphere Program (IGBP) soil dataset (Global Soil Data Task, 2000). The soil profile for the site contains more percentage of sandy $(\sim 50 \%)$ than clay $(\sim 25 \%)$ (see Fig. 4$)$. Vegetation data developed by Bonan et al. (2002), based on plant-functionaltype (PFT) classification, is used for this study. Derived from the land cover dataset of IGBP (Loveland et al., 2000), the dataset consists of seven primary PFTs (needleleaf evergreen or deciduous trees, broadleaf evergreen or deciduous trees, shrubs, grasses, and crops) at $0.5^{\circ}$ latitude-longitude resolution. Important vegetation parameters that are extracted from the data include the dominant PFTs for the study sites and the associated fractional coverage, leaf-area-index, vegetation height, and root parameters. LAI is allowed to vary seasonally, while the fractional vegetation cover and other vegetation prosperities are assumed constant. For the model, area-weighted average values of the vegetation properties of the dominant PFTs are used. The dominant PFTs for the study site consist of needleleaf evergreen trees (46\%), grasses $(52 \%)$, and broadleaf deciduous trees $(2 \%)$. The various parameter values used in the model are given in Table A1.

\section{Results and discussions}

In this study, to investigate the effect of hydraulic redistribution by plant roots on terrestrial climatology, we setup two simulation scenarios, which are described as follows:

Case1 - No hydraulic redistribution: In this case, HR is not considered. As opposed to Eq. (14), this case uses Eq. (2) for simulating the soil moisture profile and Eq. (1) for modeling the water uptake by roots. In essence, this is same as the modeling approaches used in current land-surface models.

Case2 - With hydraulic redistribution: In this case, HR is considered, and Eq. (14) is the governing equation for simulating the soil moisture and the root water uptake profiles.

For both cases, the rooting depth is set to $10 \mathrm{~m}$, and the root distribution profile is defined by logistic function as given by Eq. (16) (see Fig. 4). The simulations are performed for $27 \mathrm{yr}$ (covering the period 1979-2005). At the start, the soil column is initialized to saturation moisture content, and the simulation is repeated twice for the first year (1979) for spinup. All of the results presented here are monthly or daily average of the entire simulation period of $27 \mathrm{y}$, excluding the spin-up period.

\subsection{Hydraulically redistributed water}

Before discussing the effect of HR on terrestrial climatology, let us first look at into the quantity of water redistributed by roots, termed here as "hydraulically redistributed water" (HRW). Note that, the issue of HRW is only for Case2. The HRW at each time step is obtained by integrating the quantity of reverse flow (i.e. from the root to the soil) over all soil layers, that is,

$\mathrm{HRW}=\int_{0}^{Z_{\max }} K_{r h, r a d}\left(\psi_{s m}-\psi_{r p}\right) d z, \quad$ for $\psi_{s m}<\psi_{r p}(18)$ where $z_{\max }$ is the maximum root zone depth, here set to $10 \mathrm{~m}$. 

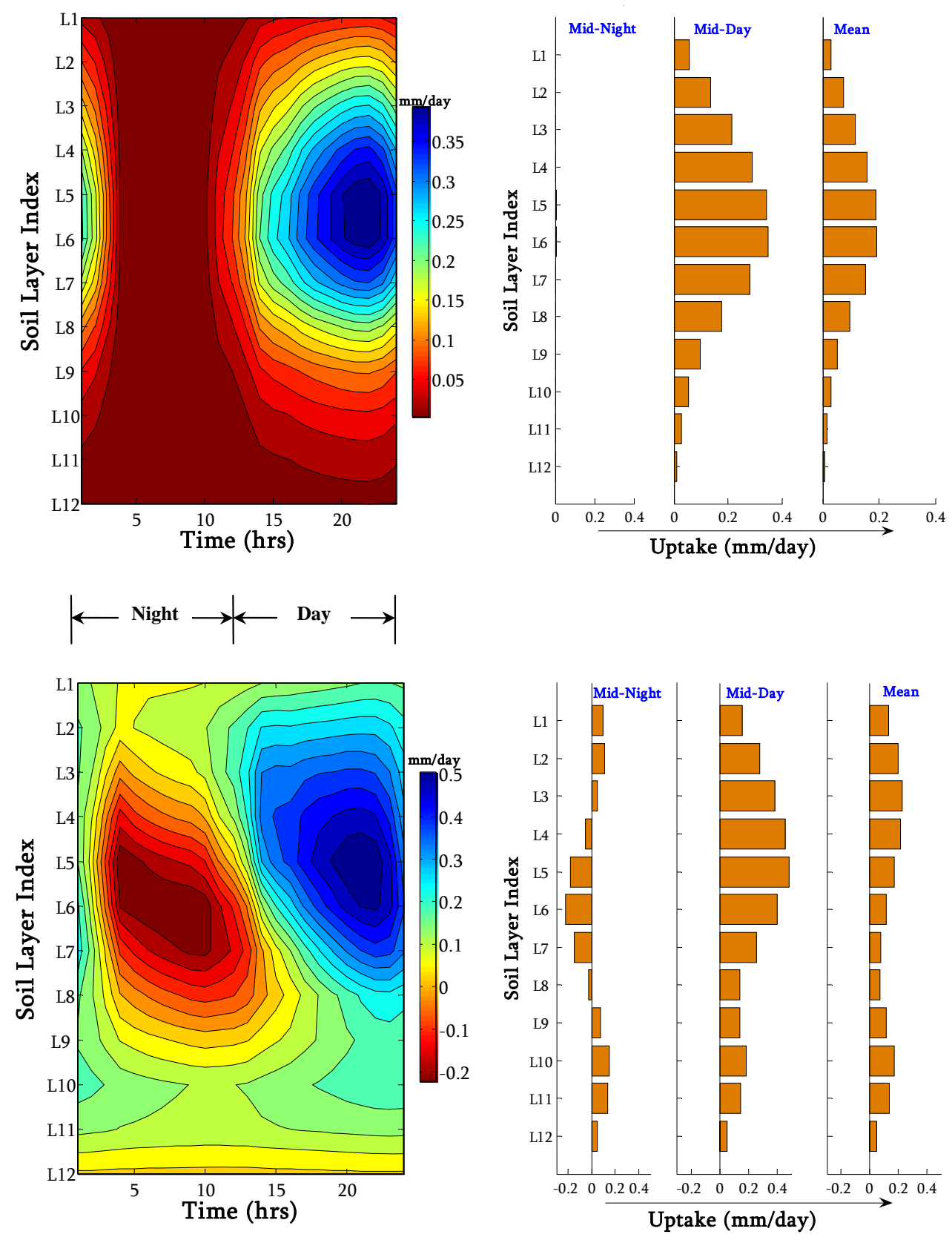

Fig. 8. Diurnal profiles of moisture uptake by plant roots for the study site: (top) without hydraulic redistribution, and (bottom) with hydraulic redistribution. The figures show the average over the entire simulation period (1979-2005).

Figure 7 compares the HRW with the transpiration rate for the study site. The average HRW is in the order of $1 \mathrm{~mm}$ per day. Compared to transpiration, the HRW has less seasonality. During summer, the HRW amounts to about $30-40 \%$ of the transpiration rate. During winter, the transpiration is very low, and the HRW can be as high as 3-4 times the transpiration rate. The HRW seems to correlate very well with precipitation, i.e. it is higher during the wet season and lower during dry season. This has the implication that the downward transfer rate of water during the wet season is larger than the upward transfer during dry summer season. This is contrary to one's expectation, but it should not be surprising as the hydraulic conductivity of the roots is higher during wet season [see Eq. (15)], leading to a large quantity of downward moisture transfer during rainy periods.

\subsection{Water uptake profile}

\subsubsection{Diurnal profile}

Figure 8 shows the diurnal root water uptake profiles for simulation cases without HR [Case1] and with HR [Case2]. The 
two cases provide dramatically different water uptake profiles. For the case without HR (Fig. 8, top panels), moisture movement takes place only from the soil to the root, and hence, the uptake is always positive. For this case, during night time, the uptake is negligible because of the stomatal closer. During day time, water is taken up from all soil layers, and the water uptake profile generally follows the root distribution profile. The peak water uptake occurs in the late afternoon (around $4 \mathrm{pm}$ ).

For the case where HR is incorporated into the model formulation (see Fig. 8, bottom panels), moisture movement between the soil and the roots is bi-directional, with moisture flow from the soil to the root or vice versa depending on the water potential gradient. In the figure, negative values indicate a moisture movement from the root to the soil, while positive values indicate movement from the soil to the root as in Case1. During night, water is transferred from relatively wet part of the soil (in this case, upper and lower soil layers) to dry part of the soil (in this case, the middle soil layers) via plant roots. During day time, water is taken up from all soil layers. The net water uptake profile, averaged over the entire period, shows a disproportionately high water uptake from the deeper soil layers with respect to the proportion of roots in those layers. A noticeable pattern is the nearly uniform uptake of moisture over the vertical profile as compared to Case 1 where the uptake is reflective of the profile of the root distribution.

\subsubsection{Seasonal profile}

Figure 9 shows the seasonal root water uptake profiles for the two simulation cases. Similar to the diurnal profiles, we see completely different water uptake patterns between the two cases. When the HR is not considered (see Fig. 9, top panels), the uptake profile is dictated by the root profile both during wet and dry seasons. Under this condition, because the total uptake is governed by transpiration, the uptake is higher during dry/summer season than during wet/winter season. During wet season, there is sufficient moisture throughout the soil profile and the uptake from each layer is directly controlled by the proportion of roots in the layers. As the rainy season starts to cease, the near surface soil moisture starts to decline at faster rate than the moisture at deeper soil layers because of the difference in the root density. As the dry season approaches, the top soil layers get drier while the bottom layers are still moister. Consequently, during dry season, in addition to the root fraction, the soil moisture level starts to control the moisture uptake, and the depth of maximum water uptake will shift down towards regions of more moist soil layers.

For the case with HR (see Fig. 9, bottom panels), the uptake profile does not correlate with the root distribution profile. During wet winter season, the upper soil is wetter than the deeper soil, and the net moisture transport via plant roots is downward (from upper soil layers to lower soil layers).
During this time, the moisture transferred to the lower layers is higher than the moisture taken up from these layers, leading to a net moisture release into the soil from the root at the lower layers (negative uptake). During dry summer season, the upper soil is drier than the deeper soil, and the net moisture transport via plant roots is upward, and moisture is released into the upper soil layers during night. The amount of moisture released into the upper soil layers during night is less than the amount taken up during day time from these layers, leading to a net positive moisture uptake. The net moisture uptake from the deeper soil layers during the summer is significantly higher than the uptake from the upper soil layer, despite the very small root proportion in the deeper soil layers.

\subsection{Soil moisture profile}

Figure 10 shows the moisture profile over the entire simulation period for both cases, indicating the influence of $\mathrm{HR}$ on the seasonal and inter-annual variability of soil moisture. The incorporation of HR has significantly changed the moisture profile. The inter-annual variation of the effect of HR on the soil moisture profile is evident from the plots. The effect is highly pronounced during consequent dry years during the mid and the last years of the simulation period. As expected, the HR results in higher net upward moisture transfer during the dry years, resulting in reduced moisture in deeper layers.

During wet season, the incorporation of HR causes a net decrease of moisture content over the whole soil profile (see Fig. 10, bottom-left). The decrease of moisture in the upper soil layers is due to the net downward transfer of water via the roots during the night (when the stomata close and transpiration ceases). However, the amount of moisture transferred from the upper to the lower layers is not sufficient to bring the moisture state of the lower layers to the level when there is no HR; thus, the deeper soil layers still have a lower soil moisture content than when there is no HR.

During dry season, the net effect of HR is a significant increase of moisture in the upper soil layers and a decrease in the lower soil layers (see Fig. 10, bottom-center). During this period, the deeper soil is often wetter than the shallower soil, leading to a net upward moisture transfer via plant roots and resulting in an increase in moisture in the upper layers and a decrease in the lower layers. The long-term net impact of the HR on soil moisture is an increase of moisture in the upper soil layers and a decrease in the lower soil layers (see Fig. 10, bottom-right). This leads to a more uniform moisture profile over the soil depth for the simulation with HR compared to the case without HR.

\subsection{Transpiration, cCarbon assimilation, and water-use- efficiency}

The model for simulating the transpiration rate $E_{t}$ is described in the Appendix [see Eqs. (A7)-(A22)]. Following 

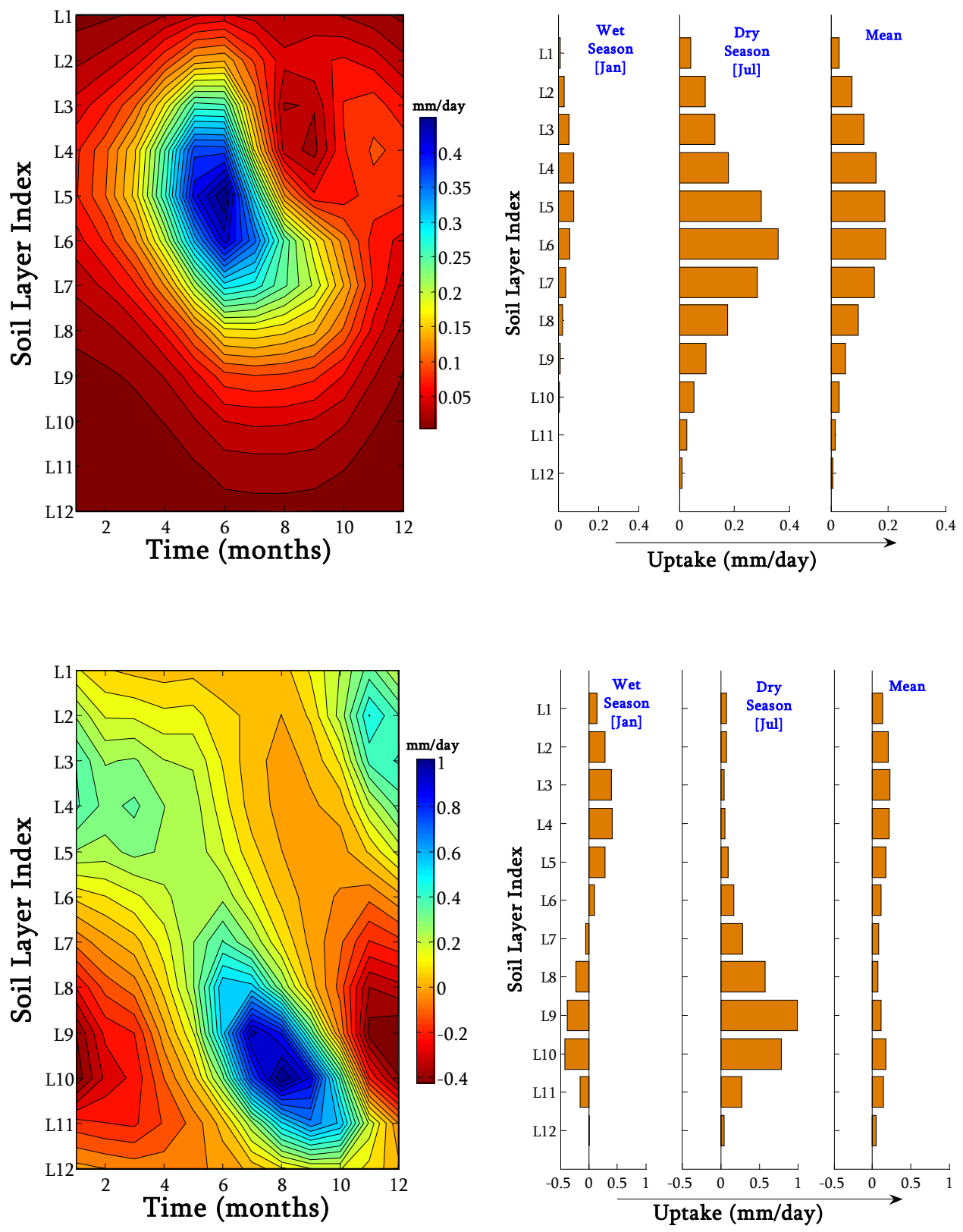

Fig. 9. Seasonal profiles of moisture uptake by plant roots for the study site: (top) without hydraulic redistribution, and (bottom) with hydraulic redistribution. The figures show the average over the entire simulation period (1979-2005).

the formulations of Farquhar et al. (1980), Collatz et al. (1991), and Leuning (1995), carbon assimilation rate is modeled as

$A=\min \left(A_{c}, A_{q}, A_{e}\right) \geq 0$

where $A$ is assimilation rate per unit leaf area, $A_{c}$ is assimilation rate limited by Ribulose Bisphosphate carboxylaseoxygenase (Rubisco) activity (i.e. assimilation limited by $\mathrm{CO}_{2}$ concentration), $A_{q}$ is assimilation rate limited by the capacity of Ribulose Bisphosphate (RuPB) regeneration through electron transport (i.e. assimilation limited by light), and $A_{e}$ is assimilation rate limited by the capacity to export or utilize photosynthetic products. Detail parameterization for these three limiting factors is given in the appendix. Assimilation rate per unit ground area is obtained by multiplying the above equation by the leaf-area-index $(L A I)$. Where moisture supply is limiting during parts of the year, as is the case for the study site, plants often strive to maximize their water-use-efficiency (WUE), which is defined as the ratio of carbon dioxide influx to water efflux at the canopy (Fitter and 

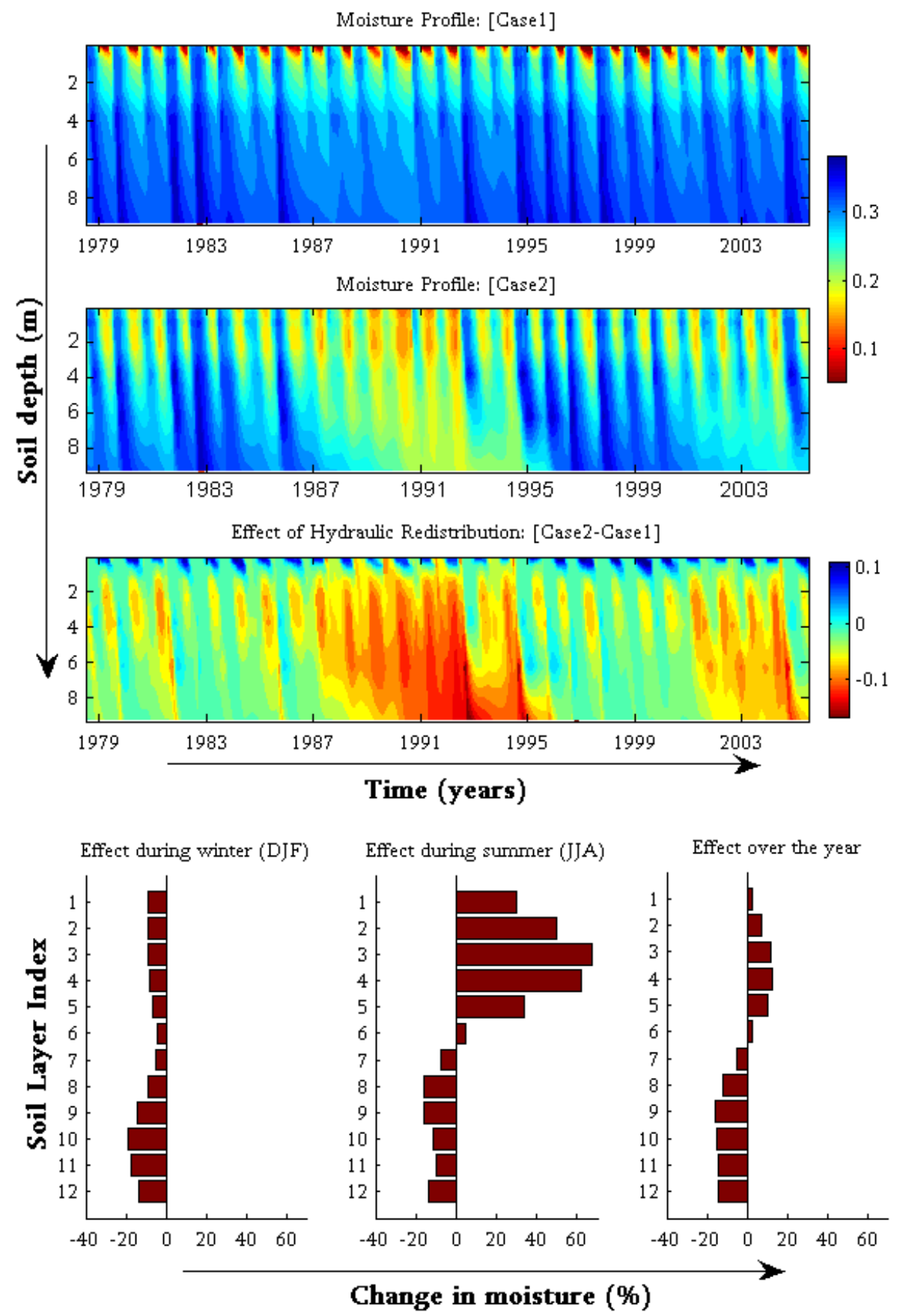

Fig. 10. Soil moisture profile over the entire simulation period (1979-2005) under Case 1 and Case 2 for the study site, showing the effect of hydraulic redistribution on the profile during different years and seasons. The percentage change is with respect to Case1.

Hay, 2002; Taiz and Zeiger, 2002; Berry et al., 2005). In this study, WUE is modeled as

$\mathrm{WUE}=\frac{A / A_{\max }}{E_{t} / E_{t, \max }}$

where $A_{\max }$ and $E_{t, \max }$ are the maximum assimilation and transpiration rates, respectively, and are used for scaling.
Figure 11 shows the annual cycles of transpiration, carbon assimilation, and WUE for both cases under consideration (with and without HR). The effect of incorporating HR into the model has resulted in the increase of all the three variables. This increase is particularly very prominent during the summer dry season. In contrast to the transpiration and assimilation, which attains their maximum during summer, the 

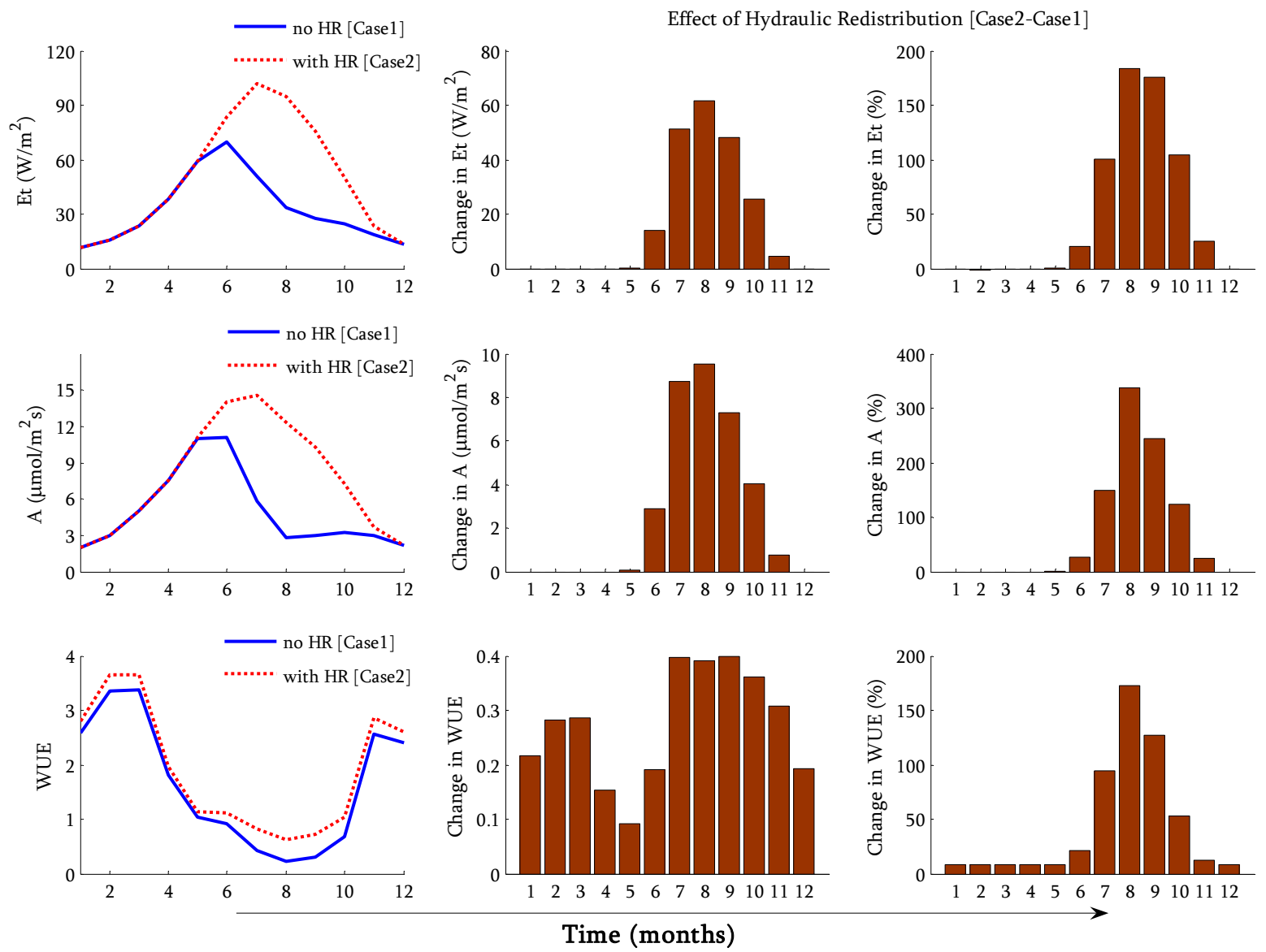

Fig. 11. Comparison of simulated annual cycles of transpiration, assimilation, and WUE for Case 1 and Case 2 for the study site. Shown is an average cycle over the simulation period (1979-2005). The percentage change is with respect to Case1.

WUE attains its maximum during the winter. It is not clear why the WUE shows this pattern although we offer a couple of explanation. First, during winter the humidity of the overlying atmosphere at the study site is high (not shown), hindering the transpiration rate with little or no effect on the assimilation rate. Second, during summer the wind speed is low for the site, increasing the leaf boundary layer resistance. Since the resistance to carbon dioxide in the boundary layer is in the order of 1.4 times the resistance offered to water (Fitter and Hay, 2002; Taiz and Zeiger, 2002), the assimilation is affected by the low wind speed more than the transpiration does.

\subsection{Bottom drainage}

Because HR alters the water uptake and the soil moisture content of the bottom soil layer, it has the potential to influence the drainage rate at the bottom of the soil column. The mechanism of HR strives to maximize the plant water usage within the root zone by reducing moisture loss from the root zone by gravity. Figure 12 shows the effect of HR on the drainage from the soil column at the bottom. The HR results in a significant decrease of the bottom drainage. This agrees with the moisture decrease observed in the bottom soil layer with the HR simulation.

The reduction of bottom drainage could have an implication on the recharge rate to the groundwater. Thus, in deeprooted vegetation environments of the arid and semiarid regions, the HR mechanism has the potential to create a barrier to deep drainage at the bottom of the root zone, while maximizing the water available to plants.

\subsection{Comparison with observations}

A unique aspect of the study presented above is the lack of any calibration to match the model performance to observations. However, it is important to assess the predictive capability of the model through comparison with observations. Observations of subsurface hydrological variables, such as soil moisture and water uptake are often rare to find. Particularly, observations of deep-soil processes are non-existent. Therefore, in this study, we use surface and near-surface observations of available datasets to validate some of the results. Here, we make use of the soil moisture and latent heat 

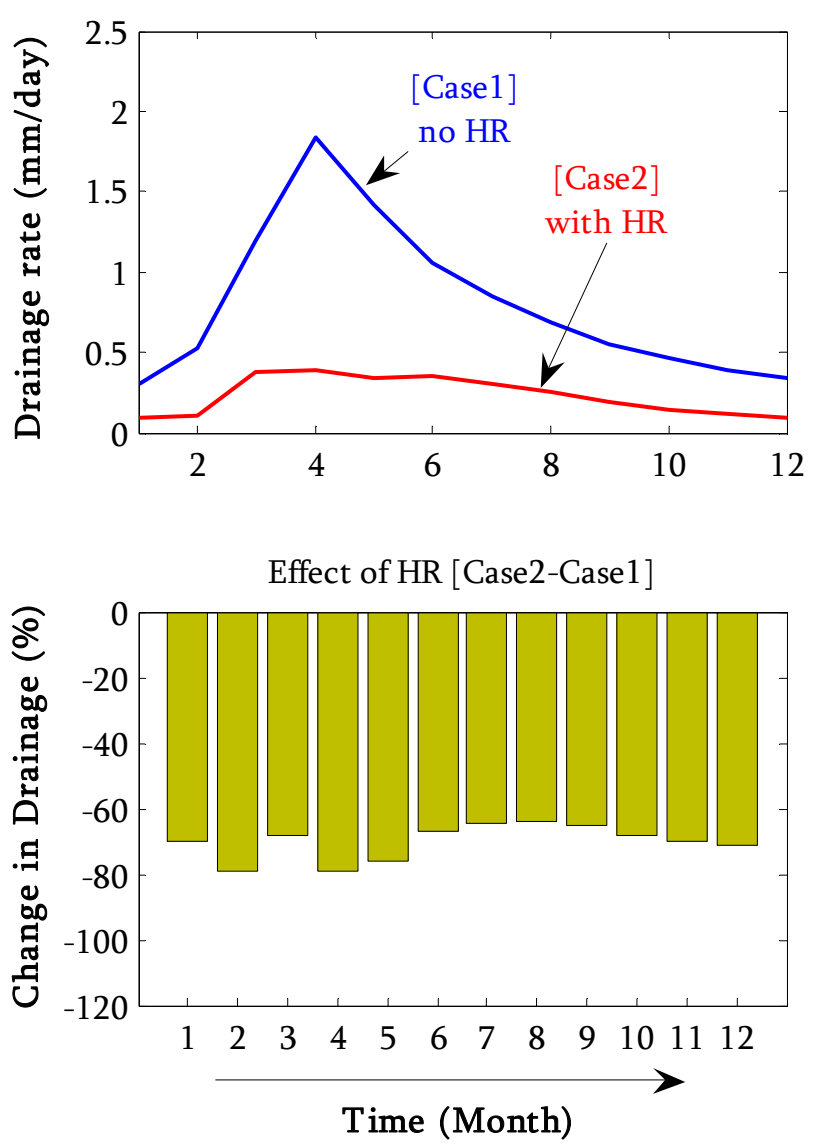

Fig. 12. Comparison of simulated annual cycles of bottom drainage for Case 1 and Case 2 for the study site. Shown is an average cycle over the simulation period (1979-2005). The percentage change shown is with respect to Case1.

flux observations at the nearby FLUXNET station (see Baldocchi et al., 2001) for this purpose. The FLUXNET station available in the vicinity of the study site is the Blodgett station, located at $38^{\circ} 54^{\prime} \mathrm{N}$ and $120^{\circ} 38^{\prime} \mathrm{W}$ in the Sierra Nevada ecosystem, having similar vegetation and climate as the study site. In contrast to the long-term model simulation (19792005), the available observation at the Blodgett station covers only a short period from 1999 to 2005. Further, the soil moisture data is available only for the surface layer.

Figure 13 (left panels) show comparison between the simulated soil moisture of the top soil layer at the study site for the two cases and the observed soil moisture at the Blodgett station. The soil moisture simulation captures the general trend. We should not expect a close match because while the simulations represent the average of a $0.5^{\circ}$ latitude-longitude grid, the observations provide point values. Figure 13 (right panels) show similar comparison for the latent heat flux. The plots are based on the average over the observation period [i.e. 1999-2005]. There is a reasonable agreement between the simulated and observed datasets. Note that the simulated latent heat flux when HR is incorporated [Case2] is in a better agreement with the observation. In particular, note the improved correspondence during the summer dry period where the deeper layer provides the moisture to meet the evaporative demand. This indicates that the negligence of HR mechanism in land-surface models could potentially underestimate the latent heat flux form vegetated surfaces in water-limited environments and consequently the entire surface energy balance and its impact on the climate system. This issue is under investigation.

\section{Summary and conclusions}

The focus of this work is the development of a multi-layer model to characterize hydraulic redistribution by vegetation roots, particularly in environments that experience water limitation. The HR is modeled by assuming the plant root system as a conduit for moisture transport along a pressure gradient.

The developed model is able to capture water uptake patterns induced by hydraulic redistribution. When comparing with the simulation without HR, the incorporation of HR resulted in sizable alteration in the profiles of soil moisture and water uptake. It has also tremendously intensified the canopy transpiration and the associated carbon assimilation and water-use-efficiency (WUE) during dry-summer season. For the study site the average percentage increase in transpiration, assimilation, and WUE are 53\%, 56\%, and $17 \%$, respectively. Simulation with HR produced better agreement with observation of latent heat flux.

The HR phenomenon makes the presence of roots much more important than their abundance for the deep soil layers. This study shows that HR enhances tremendously the contribution of deep roots to the water uptake by plants. The quantity of moisture taken up from deep soil layers is disproportionately high when compared to the proportion of roots at those depths. HR can be seen as a mechanism by which the vegetation makes optimal use of available water. It appears to be a water conservation mechanism for the plant's usage that has adaptive importance and is most significant when deep roots are present. The mechanism may allow the plant to survive under extended dry periods.

In general, the redistribution of soil water by plant roots is an important component of below-ground hydrological processes and, in conjunction with deep-rooting, forms strong linkage between the long-memory deep-soil reservoir (see Amenu et al., 2005) and the relatively short-memory atmospheric system. By enhancing the effectiveness of water uptake by plant roots from long-memory deep soil reservoirs, the HR mechanism may have the potential to influence the predictability of climate at seasonal and longer time scales and need to be considered in any hydroclimatological and/or hydroecological modeling. The HR model presented in this study can be incorporated into large scale models for further evaluation. 

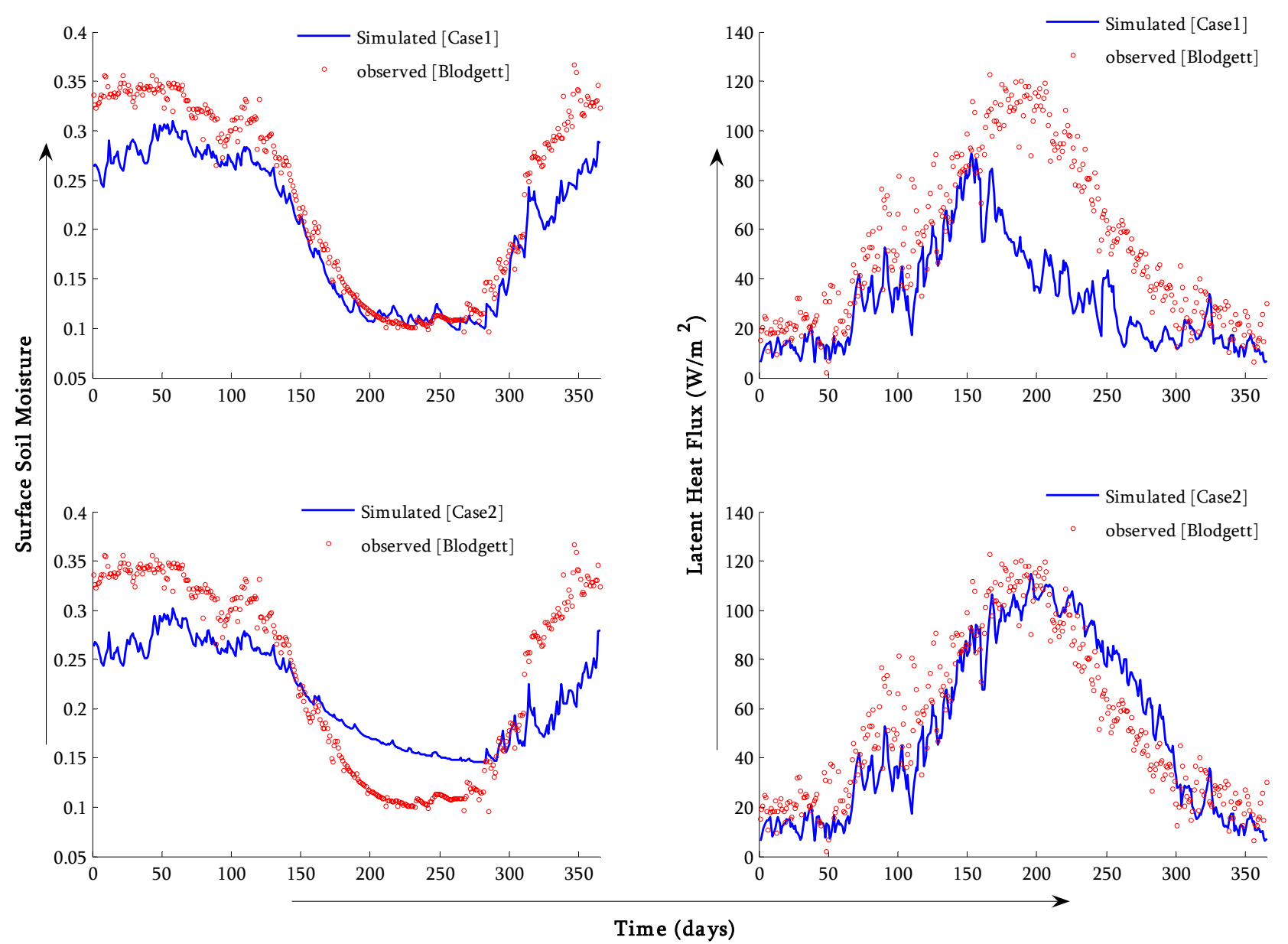

Fig. 13. Comparison of simulated and observed soil moisture (left) and latent heat flux (right) for the study site. The observation is from the nearby FLUXNET station, Blodgett station and the results depict the average over the observation period from 1999 to 2005.

One of the challenges that we will encounter in large scale implementation of the proposed model is the specification of the parameters associated with different plant functional types in various biomes. Since the new parameters proposed here deal mostly with below-ground characterization, this may be a challenging task for its widespread application. It is our belief, however, that the need for the characterization of these processes in models to attain improved predictability will be significant enough to rally a wider research community to address this problem.

\section{Appendix A}

\section{Soil Hydraulic Properties}

The hydraulic properties of soil (i.e. hydraulic conductivity and matrix potential) are functions of the soil moisture content and the soil texture, and are expressed as (Clapp and Hornberger, 1978; Oleson et al., 2004)

$$
\begin{aligned}
& K_{s h}=K_{\text {sat }}\left(\frac{\theta}{\theta_{\text {sat }}}\right)^{2 b+3} \\
& \psi_{s m}=\psi_{\text {sat }}\left(\frac{\theta}{\theta_{\text {sat }}}\right)^{-b}
\end{aligned}
$$

where the saturation values of soil hydraulic conductivity $K_{\text {sat }}$, soil matric potential $\psi_{\text {sat }}$, and volumetric soil moisture content $\theta_{\text {sat }}$ and the constant $b$ are functions of soil texture (percentages of sand and clay contents). This can be obtained as (Oleson et al., 2004)

$$
\begin{aligned}
& K_{\text {sat }}=0.0070556 \times 10^{-0.884+0.0153(\% \text { sand })} \exp (-\xi z) \\
& \psi_{\text {sat }}=-10 \times 10^{1.88-0.013(\% \text { sand })} \\
& \theta_{\text {sat }}=0.489-0.00126 \times(\% \text { sand }) \\
& b=2.91+0.159 \times(\% \text { clay })
\end{aligned}
$$

in which $\xi$ is the decay rate of $K_{\text {sat }}$ with soil depth (Beven and Kirkby, 1979). 
Table A1. Values of model parameters used in this study. These values are compiled from several studies, including Jarvis (1976), Jones (1992), Harley et al. (1992), Huang and Nobel (1994), Leuning (1995), Lhomme et al. (1998), Kim and Lieth (2003), Daly et al. (2004), and Amenu et al. (2005).

\begin{tabular}{|c|c|c|c|}
\hline Parameter & Value & Unit & Description \\
\hline$K_{\text {root,rad }}$ & $5 \times 10^{-8}$ & $\mathrm{~s}^{-1}$ & Radial conductivity of root system \\
\hline$K_{\text {root,ax }}$ & $2 \times 10^{-1}$ & $\mathrm{~mm} \mathrm{~s}^{-1}$ & Axial conductivity of root system \\
\hline$\zeta$ & 0.10 & - & Decay rate of throughfall \\
\hline$\xi$ & 0.20 & - & Decay rate of $K_{\text {sat }}$ with depth \\
\hline$\lambda$ & $2.51 \times 10^{6}$ & $\mathrm{~J} \mathrm{~K}^{-1}$ & Latent heat of vaporization \\
\hline$\gamma$ & 66.7 & $\mathrm{~Pa} \mathrm{~K}^{-1}$ & Psychrometric constant \\
\hline$\sigma$ & $5.67 \times 10^{-8}$ & $\mathrm{~W} \mathrm{~m}^{-2} \mathrm{~K}^{-4}$ & Stefan-Boltzman constant \\
\hline$\kappa$ & 0.41 & - & Von Karman constant \\
\hline$\alpha_{s}$ & 0.20 & - & Surface albedo \\
\hline$\varepsilon_{s}$ & 0.97 & - & Surface emissivity \\
\hline$C_{p}$ & 1200 & $\mathrm{~J} \mathrm{~m}^{-3} \mathrm{~K}^{-1}$ & Heat capacity of air \\
\hline$C_{\text {water }}$ & $4.18 \times 10^{6}$ & - & Heat capacity of water \\
\hline$\rho_{w}$ & 1000 & $\mathrm{~kg} \mathrm{~m}^{-3}$ & Density of water \\
\hline$d_{l}$ & 0.04 & $\mathrm{~m}$ & Leaf dimension \\
\hline$g_{s, \max }$ & 15 & $\mathrm{~mm}$ & Maximum stomatal conductance \\
\hline$k_{R}$ & 0.005 & $\mathrm{~m}^{2} \mathrm{~W}^{-1}$ & Const. for radiation function \\
\hline$k_{T}$ & 0.0016 & $\mathrm{~K}^{-2}$ & Const. for temperature function \\
\hline$k_{D}$ & 0.00285 & $\mathrm{~Pa}^{-1}$ & Const. for vapor pressure function \\
\hline$T_{\mathrm{opt}}$ & 298 & $K$ & Optimum temperature \\
\hline$\psi_{50}$ & -450000 & $\mathrm{~mm}$ & Leaf potential at $50 \%$ conductance \\
\hline$k_{S, \max }$ & $7.2 \times 10^{-5}$ & $\mathrm{~s}^{-1}$ & Max. aboveground conductance \\
\hline$\beta$ & 0.95 & - & Shape parameter \\
\hline$\alpha$ & 0.20 & mol electron $\mathrm{mol}^{-1}$ & Quantum yield \\
\hline$T_{o}$ & 293.2 & $\mathrm{~K}$ & Reference temperature \\
\hline$V_{\max o}$ & 50 & $\mu \mathrm{mol} \mathrm{m}^{-2} \mathrm{~s}^{-1}$ & Value of $V_{\max }$ at $T_{l}=T_{o}$ \\
\hline$J_{\max o}$ & 75 & $\mu$ mol electron $\mathrm{m}^{-2} \mathrm{~s}^{-1}$ & Value of $J_{\max }$ at $T_{l}=T_{o}$ \\
\hline$H_{v V}$ & 116300 & $\mathrm{~J} \mathrm{~mol}^{-1}$ & Activation energy for $V_{\max }$ \\
\hline$H_{d V}$ & 202000 & - & Deactivation energy for $V_{\max }$ \\
\hline$H_{v J}$ & 79500 & - & Activation energy for $J_{\max }$ \\
\hline$H_{d J}$ & 201000 & - & Deactivation energy for $J_{\max }$ \\
\hline$S_{v}$ & 650 & - & Entropy term \\
\hline$H_{c}$ & 59,430 & - & Activation energy for $K_{c}$ \\
\hline$H_{O}$ & 36000 & & Activation energy for $K_{O}$ \\
\hline$K_{c o}$ & 302 & $\mu \mathrm{mol} \mathrm{mol}^{-1}$ & Michaelis constant for $\mathrm{CO}_{2}$ \\
\hline$K_{o o}$ & 256000 & - & Michaelis constant for $\mathrm{O}_{2}$ \\
\hline$a_{o}$ & 34.6 & - & $\mathrm{CO}_{2}$ compensation point at $T_{o}$ \\
\hline$a_{1}$ & 0.0451 & $\mathrm{~K}^{-1}$ & Coefficient in $\Gamma_{*}$ \\
\hline$a_{2}$ & 0.000347 & $\mathrm{~K}^{-2}$ & Coefficient in $\Gamma_{*}$ \\
\hline$R_{\text {gas }}$ & 8.314 & $\mathrm{~J} \mathrm{~mol}^{-1} \mathrm{~K}^{-1}$ & Universal gas constant \\
\hline$O_{i}$ & 209000 & $\mu \mathrm{mol} \mathrm{mol}^{-1}$ & $\mathrm{O}_{2}$ concentration \\
\hline$C_{\text {atm }}$ & 350 & - & Atmospheric $\mathrm{CO}_{2}$ conc. \\
\hline
\end{tabular}

\section{Appendix B}

\section{Parameterizations for the transpiration model}

The canopy transpiration is modeled using the PenmanMonteith approach, which is given by

$E_{t}=\left[\frac{\Delta \times Q_{n}+C_{p}\left(e_{\mathrm{sat}}\left(T_{a}\right)-e_{a}\right) g_{a}}{\lambda\left[\Delta \times g_{c}+\gamma\left(g_{c}+g_{a}\right)\right]}\right] g_{c}$ where $E_{t}$ is transpiration rate, $Q_{n}$ is net external energy, $C_{p}$ is heat capacity of air at constant pressure, $e_{\mathrm{sat}}\left(T_{a}\right)$ is saturation vapor pressure at air temperature $T_{a}, e_{a}$ is actual vapor pressure, $\lambda$ is latent heat of vaporization, $\Delta$ is slope of saturation vapor pressure curve at air temperature, $\gamma$ is psychrometric constant, and $g_{c}$ and $g_{a}$ are canopy and aerodynamic conductance, respectively. The net external energy, $Q_{n}$, is estimated from 
$Q_{n}=\left(1-\alpha_{s}\right) R_{s}+\sigma\left(\varepsilon_{a} T_{\mathrm{ref}}^{4}-\varepsilon_{s} T_{s}^{4}\right)-C_{\text {soil }} \frac{\Delta T_{a}}{\Delta t} z_{e}$

where $R_{S}$ is incoming solar radiation, $\alpha_{s}$ is surface albedo, $\sigma$ is Stefan-Boltzman constant, $T_{\text {ref }}$ is air temperature at reference height (taken to be $30 \mathrm{~m}$ above the surface), $T_{s}$ is surface temperature (here, assumed equal to air temperature at $2 \mathrm{~m}$ height), $\varepsilon_{s}$ is surface emissivity, and $\varepsilon_{a}$ is atmospheric emissivity at reference height, $C_{\text {soil }}$ is soil heat capacity, $\Delta T_{a}$ is change in air temperature over time interval $\Delta t$, and $z_{e}$ is soil depth that a temperature wave penetrates over time $\Delta t$ (here, assumed equal to the thickness of the top soil layer). Following Amenu et al. (2005), the expressions for estimating $\Delta$, $e_{\text {sat }}, g_{a}, \varepsilon_{a}$, and $C_{\text {soil }}$ are as follows

$\Delta=\left(\frac{4098}{\left(237.3+T_{a}\right)^{2}}\right) \times e_{\mathrm{sat}}\left(T_{a}\right)$

$e_{\text {sat }}(T)=611 \exp \left(\frac{17.27(T-273.15)}{T-35.85}\right)$

$g_{a}=\kappa^{2} U\left[\ln \left(\frac{z_{U}-d_{o}}{z_{o m}}\right) \cdot \ln \left(\frac{z_{T}-d_{o}}{z_{o h}}\right)\right]^{-1}$

$\varepsilon_{a}=0.642\left(\frac{e_{\mathrm{sat}}\left(T_{a}\right)}{T_{a}}\right)^{1 / 7}$

$C_{\text {soil }}=C_{\text {solid }}\left(1-\theta_{\text {sat }}\right)+C_{\text {water }} \theta$

$C_{\text {solid }}=\left(\frac{2.128(\% \text { sand })+2.385(\% \text { clay })}{(\% \text { sand })+(\% \text { clay })}\right) \times 10^{6}$

where $\kappa$ is von Karman constant, $U$ is wind speed, $d_{o}$ is zero plane displacement height $\left(\approx 0.667 h_{\mathrm{veg}}\right), z_{\text {om }}$ and $z_{\text {oh }}$ are roughness length for momentum and heat transfer, respectively $\left(\approx 0.136 h_{\text {veg }}\right), h_{\text {veg }}$ is vegetation height, $C_{\text {solid }}$ is the heat capacity of the soil solid matrix, and $C_{\text {water }}$ is the heat capacity of the soil water. The canopy conductance $g_{c}$ (per unit ground area) is modeled as

$g_{c}=\left(\frac{g_{s} g_{b}}{g_{s}+g_{b}}\right) L A I$

where $L A I$ is leaf-area-index, $g_{s}$ is stomatal conductance per unit leaf area, and $g_{b}$ is leaf boundary layer conductance per unit leaf area, which can be estimated with adequate precision using (Jones, 1992)

$g_{b}=0.00662\left(\frac{U}{d_{l}}\right)^{0.5}$

where $d_{l}$ is leaf characteristic dimension. The stomatal conductance $g_{s}$ (per unit leaf area) is modeled based on Jarvis' approach (Jarvis, 1976), which is given by

$g_{s}=g_{s \max } \cdot f(R) \cdot f(T) \cdot f(\psi) \cdot f(D) \cdot f(C)$

where $g_{s \max }$ is maximum stomatal conductance per unit leaf area, and $f(R), f(T), f(\psi), f(D)$, and $f(C)$ are factors (varying between 0 and 1) that account for the constraints imposed on stomatal conductance by the radiation, temperature, leaf water status, humidity, and $\mathrm{CO}_{2}$ concentration, respectively. They are parameterized as (Noilhan and Planton, 1989; Jones, 1992; Leuning, 1995; Lhomme et al., 1998)

$$
\begin{aligned}
& f(R)=1-\exp \left(-k_{R} R_{s}\right) \\
& f(T)=1-k_{T}\left(T_{a}-T_{\mathrm{opt}}\right)^{2} \\
& f(\psi)=\left[1+\left(\frac{\psi_{\text {leaf }}}{\psi_{50}}\right)^{n}\right]^{-1} \\
& f(D)=\frac{1}{1+k_{D} D}
\end{aligned}
$$

where $k_{R}, k_{T}, k_{D}$, and $n$ are empirical constants, $T_{\text {opt }}$ is the air temperature at which the conductance attains maximum, $\psi_{\text {leaf }}$ is leaf water potential, $\psi_{50}$ is the value of leaf water potential at which $f(\psi)$ is $50 \%$ of its maximum, and $D$ vapor pressure deficit $\left(D=e_{s}-e_{a}\right)$. Because $\mathrm{CO}_{2}$ concentration in a natural environment is relatively constant over time (Jones, 1992), the factor $f(C)$ is assumed equal to 1 . The leaf water potential is linked to the soil water potential and the transpiration rate through

$\psi_{\text {leaf }}=\psi_{\text {soil }}-h_{o}\left(1+\frac{1}{K_{\text {shoot }}} E_{t}\right)$

where $K_{\text {shoot }}$ is the above ground plant hydraulic conductivity (per unit ground area), and $h_{o}$ is the reference height for leaf location above the soil surface (approximated as $\approx 0.80 h_{\mathrm{veg}}$ ).

\section{Appendix C}

\section{Parameterizations for the photosynthesis model}

The carbon-limited $A_{c}$, light-limited $A_{q}$, and exportlimited $A_{e}$ assimilation rates are given by

$$
\begin{aligned}
& A_{c}=V_{\max }\left[\frac{C_{i}-\Gamma_{*}}{C_{i}+K_{c}\left(1+\frac{O_{i}}{K_{o}}\right)}\right], \quad C_{i}-\Gamma_{*} \geq 0 \\
& A_{q}=\frac{J}{4}\left[\frac{C_{i}-\Gamma_{*}}{C_{i}+2 \Gamma_{*}}\right], \quad C_{i}-\Gamma_{*} \geq 0 \\
& A_{e}=\frac{1}{2} V_{\max }
\end{aligned}
$$

where $V_{\max }$ is the maximum carboxylation rate, $K_{c}$ and $K_{o}$ are the Michaelis-Menten coefficients for $\mathrm{CO}_{2}$ and $\mathrm{O}_{2}, \Gamma_{*}$ is the $\mathrm{CO}_{2}$ compensation point in the absence of respiration, $C_{i}$ and $O_{i}$ are internal leaf $\mathrm{CO}_{2}$ and $\mathrm{O}_{2}$ concentration, respectively, and $J$ is the electron transport rate for a given absorbed photon irradiance and is given by the smaller root 
of the following quadratic equation (Leuning, 1995; Daly et al., 2004),

$\beta J^{2}-\left(\alpha Q+J_{\max }\right) J+\alpha Q J_{\max }=0$

where $\beta$ and $\alpha$ are constants and $J_{\max }$ is the maximum rate of electron transport. The parameters $V_{\max }, J_{\max }, K_{c}, K_{o}$, and $\Gamma_{*}$ are all functions of leaf temperature, $T_{l}$, (Farquhar et al., 1980; Harley et al., 1992; Leuning, 1995; Daly et al., 2004), and are expressed as follows:

$$
\begin{aligned}
& V_{\max }=V_{\max o} \frac{\exp \left[\frac{H_{v V}}{R_{\mathrm{gas}} T_{o}}\left(1-\frac{T_{o}}{T_{l}}\right)\right]}{1+\exp \left(\frac{S_{v} T_{l}-H_{d V}}{R_{\mathrm{gas}} T_{l}}\right)} \\
& J_{\max }=J_{\max o} \frac{\exp \left[\frac{H_{v J}}{R_{\mathrm{gas}} T_{o}}\left(1-\frac{T_{o}}{T_{l}}\right)\right]}{1+\exp \left(\frac{S_{v} T_{l}-H_{d J}}{R_{\mathrm{gas}} T_{l}}\right)} \\
& K_{c}=K_{c o} \exp \left[\frac{H_{c}}{R_{\mathrm{gas}} T_{o}}\left(1-\frac{T_{o}}{T_{l}}\right)\right] \\
& K_{o}=K_{o o} \exp \left[\frac{H_{o}}{R_{\mathrm{gas}} T_{o}}\left(1-\frac{T_{o}}{T_{l}}\right)\right] \\
& \Gamma_{*}=a_{o}\left(1+a_{1}\left(T_{l}-T_{o}\right)+a_{2}\left(T_{l}-T_{o}\right)^{2}\right)
\end{aligned}
$$

where the terms are as defined in Table A1. In the above formulations, the effect of leaf water status on assimilation rate is not taken into consideration. However, such dependence is crucial for studies focusing on water-limited ecosystems. In this study Eq. (20) is reformulated as

$$
A=f(\psi) \cdot \min \left(A_{c}, A_{q}, A_{e}\right) \geq 0
$$

where the function $f(\psi)$ takes care of the water/moisture limitation on assimilation rate, and is assumed to take the same form as Eq. (A20). The intercellular $\mathrm{CO}_{2}$ concentration $C_{i}$, which is used in the calculation of the assimilation rate [see Eqs. (A23) and (A24)], is estimated from the solution of

$C_{i}^{2}+\left(g . V_{\max }-C_{\mathrm{atm}}+O\right) C_{i}-\left(g \cdot V_{\max } \Gamma_{*}+O \cdot C_{\mathrm{atm}}\right)=0$

where

$$
\left.\begin{array}{l}
O=K_{c}\left(1+\frac{O_{i}}{K_{o}}\right) \\
g=\left(\frac{1.65}{g_{s}}+\frac{1.37}{g_{b}}\right)\left(\frac{R_{\mathrm{gas}} T_{\mathrm{atm}}}{P_{\mathrm{atm}}}\right)
\end{array}\right\}
$$

in which $C_{\text {atm }}$ is atmospheric $\mathrm{CO}_{2}$ concentration, $R_{\text {gas }}$ is universal gas constant, and $P_{\text {atm }}$ is atmospheric pressure at temperature $T_{\mathrm{atm}}$. The leaf temperature, $T_{l}$, is approximated using 1st-order solution of the energy balance equation, which is given by

$$
\begin{aligned}
& T_{l}=T_{a}+ \\
& \frac{\left(1-\alpha_{s}\right) R_{s}+\left(\varepsilon_{a}-\varepsilon_{s}\right) \sigma T_{a}^{4}-G-\frac{C_{p}}{\gamma}\left(\frac{g_{c} g_{a}}{g_{c}+g_{a}}\right)\left(e_{\mathrm{sat}}\left(T_{a}\right)-e_{a}\right)}{4 \varepsilon_{s} \sigma T_{a}^{3}+C_{p}\left(\frac{\Delta}{\gamma} \frac{g_{c} g_{a}}{g_{c}+g_{a}}+g_{a}\right)}
\end{aligned}
$$

where the variables are as defined before. The values of the various parameters of the model described above are given in Table A1.

Acknowledgements. Support for this research is provided by the National Oceanic and Atmospheric Administration (NOAA) under grants NA 03-OAR4310070 and NA 06-OAR4310053 and the National Science Foundation (NSF) under grant ATM 06-28687.

Edited by: S. Manfreda

\section{References}

Amenu, G. G.: Deep-layer terrestrial hydrologic memory and mechanisms of its influence on the eco-climatology of the biosphere, Ph.D. Dissertation, University of Illinois, Urbana, 365 pp., 2007.

Amenu, G. G., Kumar, P., and Liang, X.-Z.: Interannual variability of deep-layer hydrologic memory and its influence on surface energy fluxes, J. Climate, 18, 5024-5045, 2005.

Baker, J. M., van Bavel, C. H. M.: Water transfer through cotton plants connecting soil regions of differing water potential, Agron. J., 80, 993-997, 1988.

Baldocchi, D., Falge, E., Gu, L., and et al.: FLUXNET: A new tool to study the temporal and spatial variability of ecosystem-scale carbon dioxide, water vapor, and energy flux densities, B. Am. Meteorol. Soc., 82, 2415-2434, 2001.

Berry, S. L., Farquhar, F. D., and Roderick, M. L.: Co-evolution of climate, vegetation, soil and air, in: Encyclopedia of Hydrological Sciences, 177-192, Volume 1: Theory, organisation and scale, edited by: Blöschl, G. and Sivapalan, M., John Wiley and Sons Ltd, Chichester, UK, 2005.

Beven, K. J. and Kirkby, M. J.: A physically based, variable contributing area model of basin hydrology, Hydrol. Sci. B., 24, 4369, 1979.

Brooks, J. R., Meinzer, F. C., Coulombe, R., and Gregg, J.: Hydraulic redistribution of soil water during summer drought in two contrasting Pacific Northwest coniferous forests, Tree Physiol. 22, 1107-1117, 2002.

Brooks, J. R., Meinzer, F. C., Warren, J. M., Domec, J.-C., and Coulombe, R.: Hydraulic redistribution in a Douglas-fir forest: lessons from system manipulations, Plant. Cell Environment, 29, 138-150, 2006.

Bonan, G. B., Levis, S., Kergoat, L., and Oleson, K.W.: Landscapes as patches of plant functional types: An integrating concept for climate and ecosystem models, Global Biogeochem. Cy., 16, 5.1-5.23, 2002.

Burgess, S. S. O., Adams, M. A., Turner, N. C., and Ong, C. K. The redistribution of soil water by tree root systems, Oecologia, 115, 306-311, 1998.

Burgess, S. S. O., Pate, J. S., Adams, M. A., and Dawson, T. E.: Seasonal water acquisition and redistribution in the Australian woody phreatophyte Banksia prionotes, Ann. Bot.-London, 85, 215-224, 2000.

Burgess, S. S. O., Adams, M. A., Turner, N. C., White, D. A., and Ong, C. K.: Tree roots: conduits for deep recharge of soil water, Oecologia, 26, 158-165, 2001. 
Caldwell, M. M., Dawson, T. E., and Richards, J. H.: Hydraulic lift: consequences of water efflux from the roots of plants, Oecologia, 113, 151-161, 1998.

Caldwell, M. M. and Richards, J. H.: Hydraulic lift: water efflux from upper roots improves effectiveness of water uptake by deep roots, Oecologia, 79, 1-5, 1989.

Campbell, G. S.: Simulation of Water Uptake by Plant Roots, in: Modeling Plant and Soil Systems, edited by Hanks, J. and Ritchie, J.T., American Society of Agronomy Inc, Madison, Wisconsin, 1-545, 1991.

Canadell, J., Jackson, R. B., Ehleringer, J. R., Mooney, H. A., Sala, O. E., and Schulze, E. D.: Maximum rooting depth of vegetation types at the global scale, Oecologia, 108, 583-595, 1996.

Cannon, W. A.: Specialization in vegetation and in environment in California, Plant World, 17, 223-237, 1914.

Clapp, R. B. and Hornberger, G. M.: Empirical equations for some soil hydraulic properties, Water Resour. Res., 14, 601-604, 1978.

Collatz, G. J., Ball, J. T., Grivet, C., and Berry, J. A.: Physiological and environmental regulation of stomatal conductance, photosynthesis, and transpiration: A model that includes a laminar boundary layer, Agr. Forest Meteorol., 54, 107-136, 1991.

Corak, S. J., Blevins, D. G., and Pallardy, S. G.: Water transfer in alfalfa/maize association: survival of maize during drought, Plant Physiol., 84, 582-586, 1987.

Dai, Y., Zeng, X., Dickinson, R. E., and et al.: The common land model, B. Am. Meteorol. Soc., 84, 1013-1023, 2003.

Daly, E., Porporato, A., and Rodriguez-Iturbe, I.: Coupled dynamics of photosynthesis, transpiration, and soil water balance, PartI: Upscaling from hourly to daily level, J. Hydrometeorol., 5, 546-558, 2004.

Dawson, T. E.: Hydraulic lift and water use by plants: implications for water balance, performance and plant-plant interactions, Oecologia, 95, 565-574, 1993.

Dawson, T. E.: Determining water use by trees and forests from isotopic, energy balance and transpiration analysis: the roles of tree size and hydraulic lift, Tree Physiol., 16, 263-272, 1996.

Dawson, T. E. and Pate, J. S.: Seasonal water uptake and movement in root systems of Australian phraeatophytic plants of dimorphic root morphology: a stable isotope investigation, Oecologia, 107, 13-20, 1996.

Dixon, H. H.: Transpiration and the ascent of sap in plants, MacMillan, London, 216 pp., 1914.

DeSouza, J., Silka, P. A., and Davis, S. D.: Comparative physiology of burned and unburned Rhus laurina after chaparral wildfire, Oecologia, 71, 63-68, 1986.

Emerman, S. H. and Dawson, T. E.: Hydraulic lift and its influence on the water content of the rhizosphere: an example from sugar maple, Acer saccharum, Oecologia, 108, 273-278, 1996.

Espeleta, J. F., West, J. B., and Donovan, L. A.: Species-specific patterns of hydraulic lift in co-occurring adult trees and grasses in a sandhill community, Oecologia, 138, 341-349, 2004.

Farquhar, G. D., von Caemmerer, S., and Berry, J. A.: A biochemical model of photosynthetic $\mathrm{CO}_{2}$ assimilation in leaves of $\mathrm{C}$ species, Planta, 149, 78-90, 1980.

Fiscus, E. L.: The interaction between osmotic- and pressureinduced water flow in plant roots, Plant Physiol., 55, 917-922, 1975.

Fitter, A. H. and Hay, R. K. M.: Environmental physiology of plants, Academic Press, London, 3. Ed., 1-367, 2002.
Frensch, J. and Steudle, E.: Axial and radial hydraulic resistance to roots of maize, Plant Physiol., 91, 719-726, 1989.

Gregory, P. J.: Plant Roots: Growth, activity, and interactions with the soils, Blackwell Publishing, Oxford, 1-318, 2006.

Gurevitch, J., Scheiner, S. M., and Fox, G. A.: The ecology of plants, Sinauer Associates, Inc., Sunderland, Massachusetts, 1523, 2002.

Harley, P. C., Thomas, R. B., Reynolds, J. F., and Strain, B. R.: Modelling photosynthesis of cotton grown in elevated $\mathrm{CO}_{2}$, Plant Cell Environ., 15, 271-282, 1992.

Hacke, U. G., Sperry, J. S., Wheeler, J. K., and Castro, L.: Scaling of angiosperm xylem structure with safety and efficiency, Tree Physiol., 26, 689-832, 2006.

Hellmers, H., Horton, J. S., Juhren, G., and O'Keefe, J.: Root systems of some chaparral plants in southern California, Ecology, 36, 667-678, 1955.

Huang, B. and Nobel, P. S.: Root hydraulic conductivity and its components, with emphasis on desert succulents, Agron. J., 86, 767-774, 1994.

Hultine, K. R., Cable, W. L., Burgess, S. S. O., and Williams, D. G.: Hydraulic redistribution by deep roots of a Chihuahuan Desert phreatophyte, Tree Physiol., 23, 353-360, 2003.

Hultine, K. R., Scott, R. L., Cable, W. L., Goodrich, D. C., and Williams, D. G.: Hydraulic redistribution by a dominant, warmdesert phreatophyte: seasonal patterns and response to precipitation pulses, Funct. Ecol., 18, 530-538, 2004.

Jackson, R. B., Moore, L. A., Hoffmann, W. A., Pockman, W. T., and Linder, C. R.: Ecosystem rooting depth determined with caves and DNA, Proc. Natl. Acad. Sci., 96, 11 387-11 392, 1999.

Jarvis, P. G.: The interpretation of the variations in leaf water potential and stomatal conductance found in canopies in the field, Philos. Tr. R. Soc. B, 273, 593-610, 1976.

Jones, H. G.: Plants and Microclimate: A quantitative approach to environmental plant physiology, Cambridge University Press, Cambridge, 2. Ed., 1-428, 1992.

Kim, S.-H. and Lieth, J. H.: A Coupled model of photosynthesis, stomatal conductance and transpiration for a rose leaf, Ann. Bot.London, 91, 771-781, 2003.

Kramer, P. J.: The absorption of water by the root systems of plants, Am. J. Bot., 19, 148-164, 1932.

Kramer, P. J. and Boyer, J. S.: Water relations of plants and soils, Academic Press, 2. Ed., San Diego, 1-495, 1995.

Kundu, P. K. and Cohen, I. M.: Fluid mechanics, Academic Press, 2. Ed., San Diego, 1-730, 2002.

Lee, J.-E., Oliveira, R. S., Dawson, T. E., and Fung, I.: Root functioning modifies seasonal climate, P. Natl. Acad. Sci-Biol., 102, 17 576-17 581, 2005.

Leffler, A. J., Peek, M. S., Ryel, R. J., Ivans, C. Y., and Caldwell, M. M.: Hydraulic redistribution through the root systems of Senesced plants, Ecology, 86, 633-642, 2005.

Leuning, R.: A critical appraisal of a combined stomatalphotosynthesis model for C3 plants, Plant Cell Environ., 18, 339-355, 1995.

Lewis, D. C. and Burgy, R. H.: The relationship between oak tree roots and ground water in fractured rock as determined by tritium tracing, J. Geophys. Res., 69, 2579-2588, 1964.

Lhomme, J. P., Elguero, E., Chehbouni, A., and Boulet, G.: Stomatal control of transpiration: examination of Monteith's formulation of canopy resistance, Water Resour. Res., 34, 2301-2308, 
1998.

Liang, X., Lettenmaier, D. P., Wood, E. F., and Burges, S. J.: A simple hydrologically based model of land surface water and energy fluxes for general circulation models, J. Geophys. Res., 99, 14 415-14 428, 1994.

Lopez, F. and Nobel, P. S.: Root hydraulic conductivity of two cactus species in relation to root age, temperature, and soil water status, J. Exp. Bot., 42, 143-149, 1991.

Loveland, T. R., Reed, B. C., Brown, J. F., Ohlen, D. O., Zhu, Z., Yang, L., and Merchant, J. W.: Development of a global landcover characteristics database and IGBP DISCover from $1 \mathrm{~km}$ AVHRR data, Int. J. Remote Sens., 21, 1303-1330, 2000.

Ludwig, F., Dawson, T. E., Kroon, H., Berendse, F., and Prins, H.H. T.: Hydraulic lift in Acacia tortilis trees on an East African savanna, Oecologia, 134, 293-300, 2003.

Mesinger, F., DiMego, G., Kalnay, E., and et al.: North American Regional Reanalysis, B. Am. Meteorol. Soc., 87, 343-360, 2006.

Millikin, I. C. and Bledsoe, C. S.: Seasonal and diurnal patterns of soil water potential in the rhizosphere of blue oaks: evidence for hydraulic lift, Oecologia, 125, 459-465, 2000.

Monteith, J. L. and Unsworth, M. H.: Principles of environmental physics, Edward Arnold, London, 2. Ed., 1-291, 1990.

Moreira, M. Z., Scholz, F. G., Bucci, S. J., Sternberg, L. D., Goldstein, G. H., Meinzer, F. C., and Franco, A. C.: Hydraulic lift in a neotropical savanna, Funct. Ecol., 17, 573-581, 2003.

Mooney, A., Ehrlich, P. R., Lincoln, D. E., and Williams, K. S.: Environmental controls on the seasonality of a drought deciduous shrub, Diplacus aurantiacus and its predator, the checkerspot butterfly, Euphydryas chalcedona. Ibid., Oecologia, 45, 143-146, 1980

Nobel, P. S., Schulte, P. J., and North, G. B.: Water influx characteristics and hydraulic conductivity for root of Agave deserti Engelm., J. Exp. Bot., 41, 409-415, 1990.

Noilhan, J. and Planton, S.: A simple parameterization of land surface processes for meteorological models, Month. Weather Rev., 117, 536-549, 1989.

Oleson, K. W., Dai, Y., Bonan, G., and et al.: Technical description of the community land model (CLM), NCAR Technical Note, Boulder, CO, 1-174, 2004.

Oliveira, R. S., Dawson, T. E., Burgess, S. S. O., and Nepstad, D. C.: Hydraulic redistribution in three Amazonian trees, Oecologia, 145, 354-363, 2005.

Pate, J. S., Jeschke, W. D., and Aylward, M. J.: Hydraulic architecture and xylem structure of the dimorphic root systems of southwest Australian species of Proteaceae, J. Exp. Bot., 46, 907-915, 1995.

Philip, J. R.: Plant water relations: some physical aspects, Ann. Rev. Plant Physio., 17, 245-268, 1966.

Ren, D., Xue, M., and Henderson-Sellers, A.: Incorporating hydraulic lift into a land surface model and its effects on surface soil moisture prediction, J. Hydrometeorol., 5, 1181-1191, 2004.
Richards, J. H. and Caldwell, M. M.: Hydraulic lift: substantial nocturnal water transport between soil layers by Artemisia tridentata roots, Oecologia, 73, 486-489, 1987.

Ryel, R. J., Caldwell, M. M., Yoder, C. K., Or, D., and Leffler, A. J.: Hydraulic redistribution in a stand of Artemisia tridentata: evaluation of benefits to transpiration assessed with a simulation model, Oecologia, 130, 173-184, 2002.

Schenk, H. J. and Jackson, R. B.: The global biogeography of roots, Ecol. Monogr., 72, 311-328, 2002.

Schulze, E.-D., Caldwell, M. M., Canadell, J., Mooney, H. A., Jackson, R. B., Parson, D., Scholes, R., Sala, O. E., and Trimborn, P.: Downward flux of water through roots (i.e. inverse hydraulic lift) in dry Kalahari sands, Oecologia, 115, 460-462, 1998.

Smith, D. M., Jackson, N. A., Roberts, J. M., and Ong, C. K.: Reverse flow of sap in tree roots and downward siphoning of water by Grevillae robusta, Funct. Ecol., 13, 256-264, 1999.

Song, Y., Kirkham, M. B., Ham, J. M., and Kluitenberg, G. J.: Rootzone hydraulic lift evaluated with the dual-probe heatpulse technique, Aust. J. Soil Res., 38, 927-935, 2000.

Steudle, E.: Water uptake by plant roots: an integration of views, Plant Soil, 226, 45-56, 2000.

Steudle, E. and Frensch, J.: Water transport in plants: role of the apoplast, Plant Soil, 187, 67-79, 1996.

Steudle, E. and Peterson, C. A.: How does water get through roots?, J. Exp. Bot., 49, 775-788, 1998.

Stone, E. L. and Kalisz, P. J.: On the maximum extent of tree roots, Forest Ecol. Manag., 46, 59-102, 1991.

Taiz, L. and Zeiger, E.: Plant Physiology, Sinauer Assoc. Inc. Publ., Sunderland, Mass., 3rd edition, 1-690, 2002.

Thomas, C. M. and Davis, S. D.: Recovery patterns of three chaparral shrub species after wildfire, Oecologia, 80, 309-320, 1989.

Tyree, M. T. and Zimmermann, M. H.: Xylem structure and the ascent of sap., Springer-Verlag, 2. Ed., Berlin, 250 pp., 2002.

Van Bavel, C. H. M. and Baker, J. M.: Water transfer by plant roots from wet to dry soil, Naturwissenschaften, 72, 606-607, 1985.

Van den Honert, T. H.: Water transport as a catenary process, Discuss. Faraday Soc., 3, 146-153, 1948.

Wan, C., Sosebee, R. E., and McMichael, B. L.: Hydraulic properties of shallow vs. deep lateral roots in semiarid shrub, Gutierrezia sarothrae, Am. Midl. Nat., 131, 120-127, 1994.

Wan, C., Sosebee, R. E., and McMichael, B. L.: Does hydraulic lift exist in shallow-rooted species? A quantitative examination with a half-shrub Gutierrezia sarothrae, Plant Soil, 153, 11-17, 1993.

Wan, C., Xu, W., Sosebee, R. E., Machado, S., and Archer, T.: Hydraulic lift in drought-tolerant and -susceptible maize hybrids, Plant Soil, 219, 117-126, 2000

Wetzel, P. J. and Boone, A.: A parameterization for landatmosphere-cloud-exchange (PLACE): documentation and testing of a detailed process model of the partly cloudy boundary over heterogeneous land, J. Climate, 8, 1810-1837, 1995.

Yoder, C. K. and Nowak, R. S.: Hydraulic lift among native plant species in the Mojave Desert, Plant Soil, 215, 93-102, 1999. 